\title{
Nutritional supplementations and administration considerations for sarcopenia in older adults
}

\author{
Farnaz Farshidfar $^{\mathrm{a}, \mathrm{b}}$, Veronika Shulgina ${ }^{\mathrm{a}}$ and Semone B. Myrie $\mathrm{e}^{\mathrm{a}, \mathrm{b}, *}$ \\ ${ }^{a}$ Department of Human Nutritional Sciences, Faculty of Agricultural and Food Sciences, University of Manitoba, \\ Winnipeg, Canada \\ ${ }^{\mathrm{b}}$ Richardson Centre for Functional Foods and Nutraceuticals, University of Manitoba, Winnipeg, Canada
}

\begin{abstract}
Sarcopenia is a progressive degenerative disorder affecting $\geq 40 \%$ of older adults over the age of 70 years. It is characterized by involuntary muscle loss leading to functional disability, weakness, and frailty in the elderly. Numerous mechanisms have been suggested as potential contributors to sarcopenia onset, including anorexia of aging, protein imbalances, and oxidative stress. While consensus preventive and management approaches for sarcopenia are not yet clearly defined, it is unquestionable that nutrition plays a critical role. This review focuses on the more widely studied, potent nutrients used to attenuate sarcopenia: protein/amino acids, vitamin D and calcium, antioxidants and omega-3 fatty acids. In efforts to achieve optimum delivery of these nutrients to target tissues in older adults it is important to also consider the issue of compromised digestive system that occurs with aging, which will contribute to suboptimal nutrients absorption and utilization. Therefore, this review aims to summarize key sarcopenia-attenuating nutrients and to distinguish for each identified nutrient whether a dietary or a supplemental form is the most effective therapy for nutrient delivery in sarcopenic older adults.
\end{abstract}

Keywords: Sarcopenia, skeletal muscle, dietary supplements, proteins, amino acids, vitamin D, calcium, antioxidants, omega3 fatty acids

\section{Introduction}

In 1989 Irwin Rosenberg coined the term "sarcopenia", which is derived from Greek roots, i.e. sarx: flesh and penia: loss [1]. Rosenberg's intent was to use the term sarcopenia to provide a distinct classification for age-related muscle mass loss in order to increase awareness of this condition's impact on aging [2]. Sarcopenia is a common geriatric condition defined as an age-related involuntary loss of muscle mass and function (strength or performance), leading to weakness and frailty $[2,3]$ and greater risk of falls and functional disability in older adults [4]. Globally, as the aging population continues to grow, the

\footnotetext{
*Corresponding author: Semone B. Myrie, Department of Human Nutritional Sciences, University of Manitoba, R3T 2N2, Winnipeg, Canada. Tel.: +1 204494 7290, Fax: +1 204474 7593; E-mail: myrie@cc.umanitoba.ca.
}

number of people with sarcopenia increases dramatically. Although the prevalence of sarcopenia is higher in individuals older than 60 years old, accounting for 5 to $13 \%$ of adults in this age category, it may begin as early as the forth decade of life [5]. Worldwide, $40 \%$ of the elderly population over the age of 70 years old suffers from sarcopenia, representing more than 50 million people. This number is expected to rise to 500 million people by the year 2050 [6]. The health problems associated with aging cause health systems to face mounting cost pressures and shortages of health care providers [7]. In addition, sarcopenia is associated with major co-morbidities including obesity [8], osteoporosis [9], metabolic syndrome [10] and type II diabetes [11]. Thus, due to its debilitating nature and a strong predisposition to multiple comorbidities in the elderly population, the research in the area of sarcopenia is expanding exponentially. 


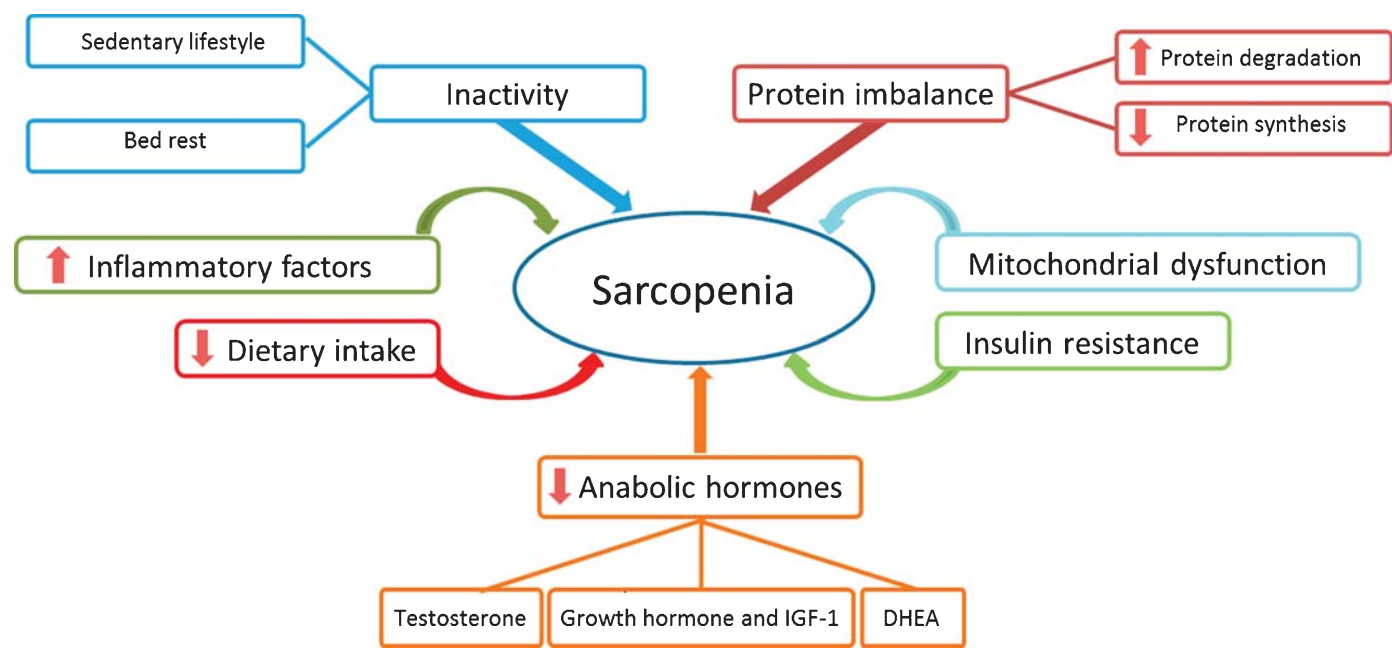

Fig. 1. Possible Etiological Factors Associated with Sarcopenia. Sedentary life style and bed rest in older adults are the major causes of inactivity, which leads to loss of the skeletal muscle mass and atrophy. Inadequate food intake and malnutrition result in impaired skeletal muscle maintenance. Furthermore, mitochondrial dysfunction, insulin resistance and inflammation are regarded as common linking factors associated with sarcopenia. Decreased level of anabolic hormones, resistance to anabolic stimulus, decreased muscle protein synthesis and increased muscle protein degradation are among the most important etiologic factors resulting in sarcopenia in older adults. DHEA indicates dehydroepiandrosterone; IGF-1, Insulin-like growth factor 1.

Although the etiology of sarcopenia is still not clearly understood many investigations have highlighted roles of both genetic and environmental factors in contributing to the development of this condition. Current understanding of possible etiologic factors associated with sarcopenia can be classified as outlined in Fig. 1 [12-14]. While consensus preventive and management approaches for sarcopenia are not yet clearly defined, it is unquestionable that nutrition plays a critical role [15-17]. A large body of literature supports the principal role of nutrition as a part of life style modification in maintaining and/or increasing muscle mass and functionality $[17,18]$. However, decline in food intake as a consequence of physiological changes or mental and physical impairments in senescent population leads to malnutrition [19]. Hence, it may be necessary to supplement older adults with additional nutrients in order to attenuate age-related loss in muscle mass and function resulting from sarcopenia [20, 21]. For instance, protein is one of the key nutrients required to maintain adequate muscle mass, however, in elderly subjects, both inadequate nutritional intake and impaired adaptation of skeletal muscle to utilize amino acids may prevent adequate muscle mass maintenance [22]. Currently, nutritional guidelines for older adults recommend getting $10-35 \%$ of daily calories from protein, which may translate to $25-30 \mathrm{~g}$ of protein per meal, 3 times per day [23]. However, despite these seemingly ade- quate nutritional recommendations, research shows that even in a supervised settings such as in long term care facilities, which should allow for more adherence to nutrition guidelines, more than $50 \%$ of older adults are malnourished [24]. Malnourishment in older adults is in part related to age-related impairments in the digestive system including the impact on food digestion and nutrient absorption capabilities. Therefore, it appears reasonable to review the assessment of nutrient absorption capabilities of frail older adults in efforts to establish optimal nutritional guidelines and route of delivery to determine the most viable form of nutritional supplementation (dietary vs. pharmacological) options that would enhance the nutritional status in elders. The aim of this paper is to review key sarcopenia-attenuating nutrients and to distinguish for each identified nutrient whether a dietary or a supplemental form is the most effective therapy for nutrient delivery in sarcopenic older adults.

\section{Impaired digestion in older adults impacts nutrients intake - A key consideration in prevention and management of sarcopenia}

Outside the central nervous system, the gastrointestinal tract (GI) contains the largest number and most complex system of neurons. The GI is also closely associated with glandular organs (liver, 
pancreas, gall bladder and salivary glands), autonomic and sensory neurons, and the vasculature. Therefore, the integrated activity and interaction between all of these cell types are of key importance to proper digestion and absorption of food matter and the subsequent nutrients. However, the physiology of aging involves changes to GI cells and function, potentially disturbing neuronal interaction and thus diminishing nutritional adequacy of the diet [25]. The impairments in the GI system in the elderly start in the mouth. Weakening of oral muscles with aging might diminish swallowing and chewing ability and thus reduce adequate nutrition. In addition, loss of teeth, ill-fitted dentures, and dry mouth further diminishes the initial step of digestion, which starts in the mouth and requires adequate masticatory ability to form bolus of food prior to swallowing [26]. A recent study by Hiramatsu et al. [27] compared swallowing and chewing ability in a group of healthy older adults (OAs, $n=23$, age $76 \mathrm{y}$ ) with a group of younger healthy adults (YAs, $n=23$, age $\sim 29 \mathrm{y}$ ). The results of the study showed that pre-meal and post-meal tongue pressures were significantly higher in YAs than in OAs. The numbers of swallows were significantly higher in YAs than OAs for both pre-meal $(P<0.01)$ and post-meal $(P<0.001)$. The time interval from the initiation to the beginning of swallow after the meal was longer compared to before the meal $(P<0.05)$, and was longer in OAs compared to YAs $(P<0.001)$. These findings further confirmed that physiological changes due to aging, such as reduced muscle tone in the pharynx and esophagus increase the duration of swallowing. Moreover, functions involved in bolus formation (mastication, tongue mobility, and lip closure) seem to deteriorate with age, prolonging the meal time and resulting in oral muscles exhaustion and thus decreased swallowing ability [27]. Furthermore, slower gastric emptying and delayed proximal gastric accommodation to a meal are also observed in the elderly. These aforementioned factors contribute to anorexia of aging, including loss of appetite and early satiation, resulting in reduced nutrient availability in the elderly, which contributes to loss of skeletal muscles and thus aggravating chances of developing sarcopenia [28]. Moreover, most recent research suggests that the skeletal muscle protein synthetic response to dietary food intake is impaired in older adults. This proposed anabolic resistance is now regarded as a key factor in the etiology of sarcopenia [29].

All in all, older adults seem to suffer from a number of impairments of the GI system which interferes with nutrients utilization and thus, along with other aging associated impairments such as increased oxidative stress and inflammation, prevents adequate muscle maintenance, which results in malnutrition and sarcopenia.

\section{Nutritional supplementation in sarcopenia}

\subsection{Protein and amino acids}

Skeletal muscles serve as the largest reservoir for total body protein storage, comprising more than $50 \%$ of the total body protein content [16]. Skeletal muscle proteins are under a continuous cycle of synthesis and break down, resulting in constant renewal of muscle protein content. In younger adults there is a balance between muscle protein synthesis (MPS) and muscle protein degradation (MPD), which leads to preservation of muscle mass and inhibition of lean tissue loss. However, aging is associated with diminished muscle anabolic response to dietary proteins, which is defined as anabolic resistance [29]. In addition, age-related adverse factors cause derangement in the degradation-synthesis equilibrium; thus contributing to sarcopenia [30]. Therefore, inadequate intake of protein and other nutrients as a result of decreased appetite, chewing or swallowing difficulties, decreased gastric emptying, physical and mental impairments, medications-nutrient interactions, presence of multiple diseases, and altered hormonal responses can contribute to impaired synthesis of proteins in skeletal muscles [19]. However, recent research indicates that ingestion of $35 \mathrm{~g}$ of whey protein shows an increased rate of de novo muscle protein synthesis when compared to ingestion of $10-20 \mathrm{~g}$ of whey protein. Therefore, it appears that anabolic resistance can be partially overcome by increasing protein intake in older adults to higher than $10-35 \%$ of the acceptable macronutrient distribution range (AMDR) [29].

Several studies have been conducted to date to examine the impact of supplementation of proteins and/or different amino acid mixtures on muscle mass and function (Table 1). Research shows that ingestion of a high-protein containing diet will trigger skeletal MPS, which will be maintained for up to 5 hours following ingestion [31]. There is an inverse relationship between protein intake and appendicular lean mass loss, i.e. for an older adult being in the highest quintile of protein intake ( $18.2 \%$ total energy, $1.1 \mathrm{~g} / \mathrm{kg} /$ day) is associated with $39 \%$ less appendicular muscle mass 
loss $(P<0.05)[32]$. Researchers have also shown that different sources of protein have different effects on MPS. Wherein ingestion of high quality proteins such as whey and casein have been shown to be more effective in mitigating muscle mass loss in sarcopenia than soy proteins $[33,34]$. In addition, some studies show that protein intake, when combined with physical activity such as resistance exercise, is capable of reducing muscle mass loss in the elderly more efficiently than merely protein ingestion [35]. Overall, high quality proteins and amino acids have been shown to be effective in attenuating age-related muscle mass loss. Nevertheless dosages, combination, timing and duration of protein or amino acid supplements, and their association with exercise, are all factors requiring further studies in order to establish optimal therapeutic strategies to attenuate age-related muscle loss and decrease the number of older adults suffering from sarcopenia.

Amino acids (AA) are organic compounds composed of two functional groups: amine $\left(-\mathrm{NH}_{2}\right)$ and carboxylic acid (-COOH) [36]. They are building blocks of proteins, as well as energy substrates and signalling molecules in protein metabolism [37]. Research shows that supplementation with 8-15 g/day of essential amino acids (EAA) results in improved lean body mass (LBM) and muscle strength $[16,20]$. Among the various EAA, the branchedchain AA (BCAA), especially leucine, have been shown to have regulatory roles in enhancing MPS and reducing MPD [38, 39]. It has been said that more than $20 \%$ of the total protein content of the diet is comprised of BCAA [40]. Since the liver does not possess any aminotransferase enzyme for metabolizing BCAA, these AA reach the blood and then skeletal muscles almost with the same concentrations that they appeared in the diet [41]. Thus, supplementation with BCAA, especially leucine, can potentially be of great importance to skeletal MPS $[42,43]$. Leucine is capable of inducing protein synthesis via the activation of mammalian target of rapamycin (mTOR) complex-1 signalling pathway, which plays a central role in cell growth, cellsurvival and protein synthesis. The mTOR pathway is a conserved serine/threonine kinase involved in many signal transduction pathways within the cell, regulating cell growth and homeostasis [44]. The mTOR system is categorized as two protein complexes: mTOR complex 1 (mTORC1) and mTOR complex 2 (mTORC2). Maintaining and controlling protein synthesis are the primary roles of mTORC1, whereas the role of $\mathrm{mTORC} 2$ is less clearly perceived
[45]. While activation of mTORC1 will further phosphorylates/activates $\mathrm{p} 70$ ribosomal S6 protein kinase (p70S6K) and protein synthesis, its inhibition activates autophagy machinery to eliminate damaged components and save energy for stressful conditions [46]. Thus, due to the central role of mTOR in several signaling pathways, it is implicated in the pathogenesis of diseases in which growth and homeostasis are compromised, e.g. cancer [47], aging [48], and sarcopenia [49]. The activation of p70S6K and mTORC1 is also essential for skeletal muscle hypertrophy as it is required for the initiation of a series of mRNA translation, which encodes protein necessary for protein synthesis (Fig. 2). Moreover, mTOR is implicated in protein synthesis and degradation in myopathies $[50,51]$. Increased activation of mTOR and the subsequent hyperphosphorylation of p70S6K have been observed in aged mice [52], suggesting a role for mTOR in the pathogenesis of sarcopenia and other age-related muscle abnormalities.

Research shows that both acute and chronic supplementation with EAA in the amount of $10 \mathrm{~g}$ and in combination with $3.5 \mathrm{~g}$ leucine are capable of enhancing MPS $[42,53]$. Since the leucine content of dietary proteins is a determinant of post-prandial MPS, investigating the effect of various protein sources on MPS in regard to their leucine content is of great interest in research. Luiking et al. [34] investigated whether there was a difference in the effects of a supplement high in whey protein and leucine or a dairy productcontaining supplement on skeletal MPS in healthy older adults. The results of this study revealed that the experimental group, who received $20 \mathrm{~g}$ whey protein and $3 \mathrm{~g}$ leucine-enriched product had a higher protein fractional synthesis rate (FSR) compared with the control group who ingested $6 \mathrm{~g}$ milk protein with the same calorie content [34]. Similarly, the effects of soy and whey protein, combined with resistance exercise, on the levels of p70S6K phosphorylation were compared in thirteen healthy older men [33]. Although at 2 hours post exercise the levels of phosphorylated p70S6K increased in both whey and soy supplemented groups compared with baseline $(P<0.001)$, the level of phosphorylated p70S6K remained elevated for 4 hours post exercise $(P<0.001)$ only in the $30 \mathrm{~g}$ whey protein supplemented group. These results showed that the effect of whey protein on protein synthesis signalling pathways in skeletal muscle was more prolonged than soy protein, possibly due to higher BCAA content of whey protein and thus higher stimulation of mTOR signaling pathway. However, more research is needed to better under- 


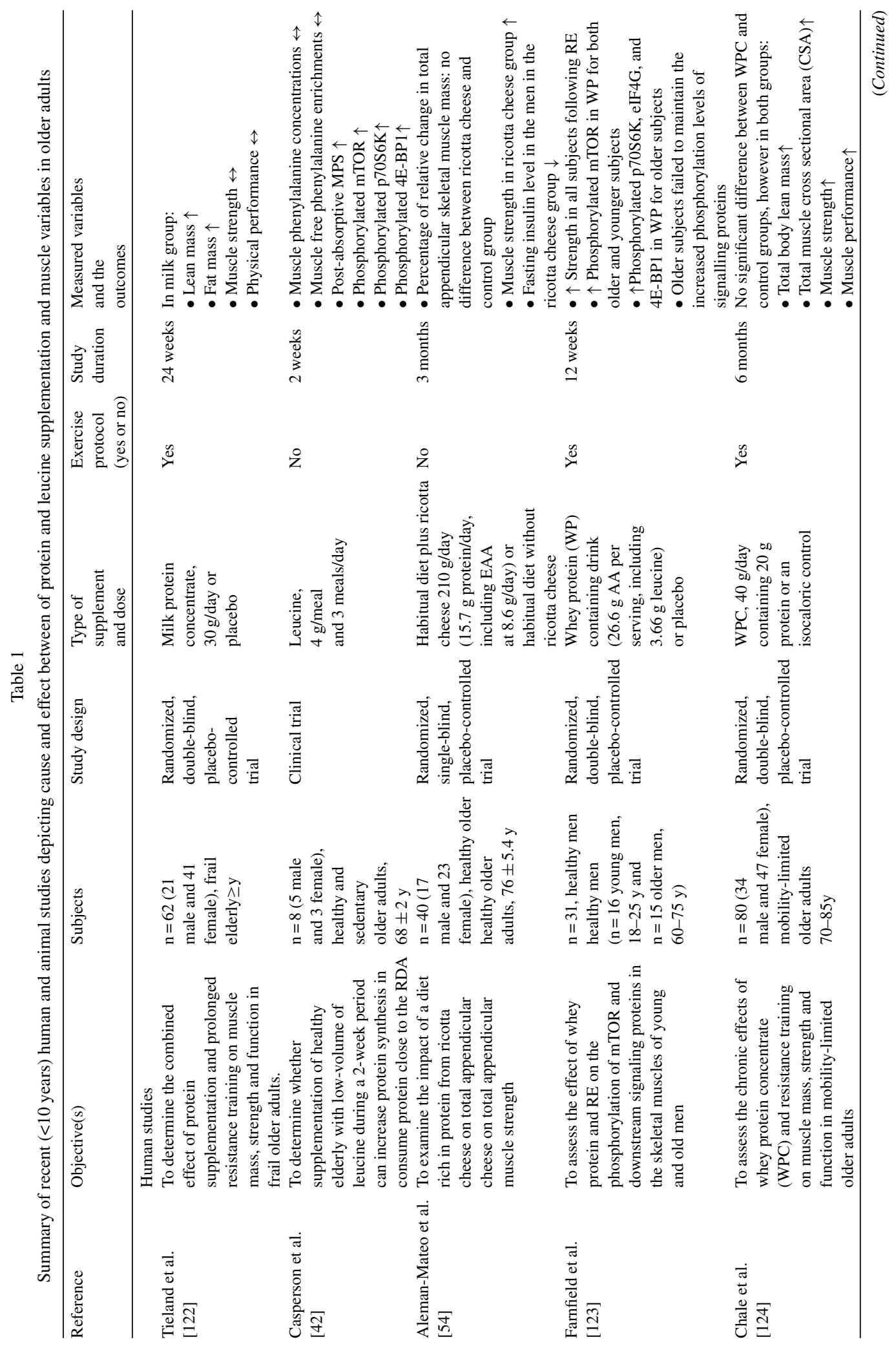




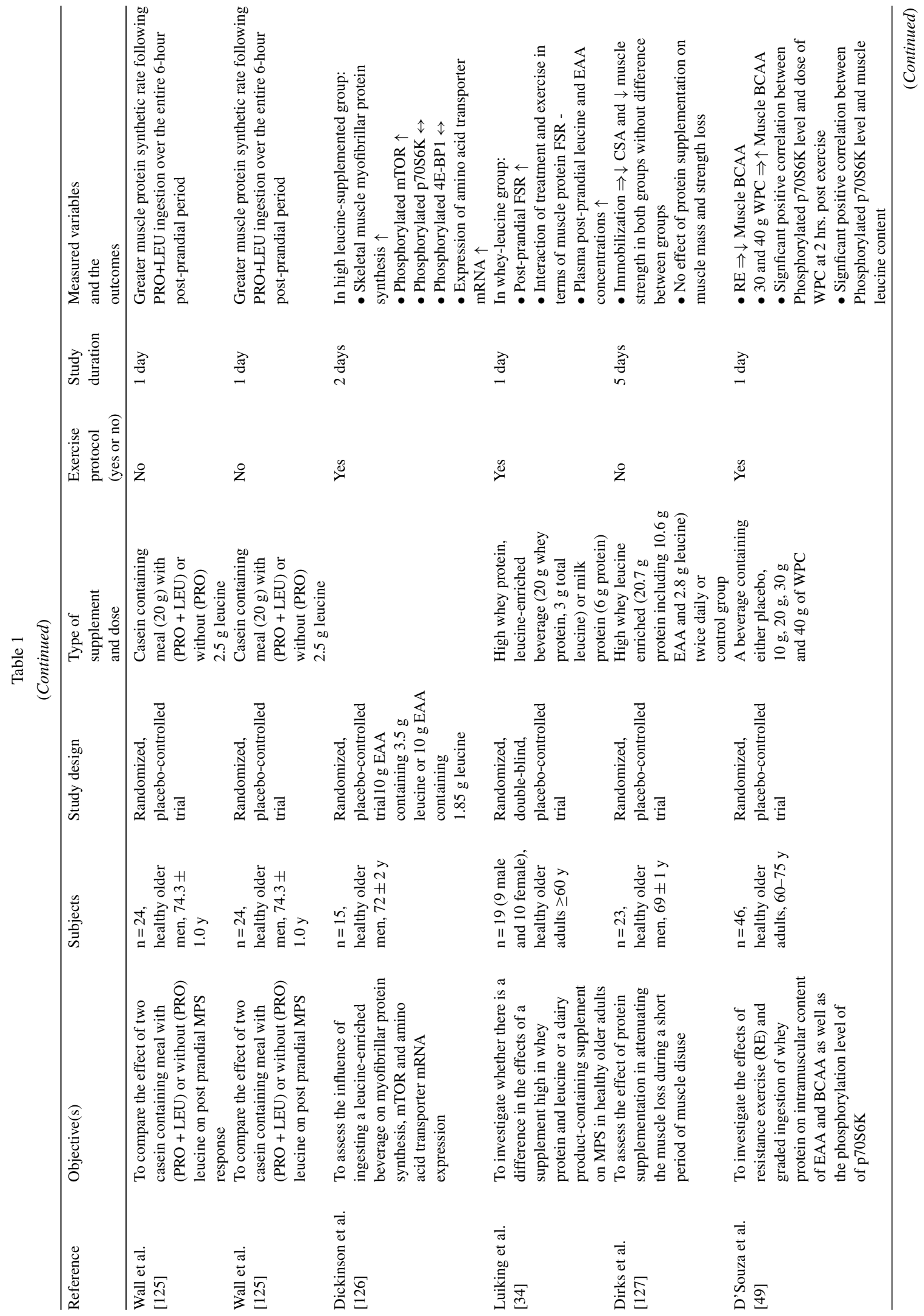




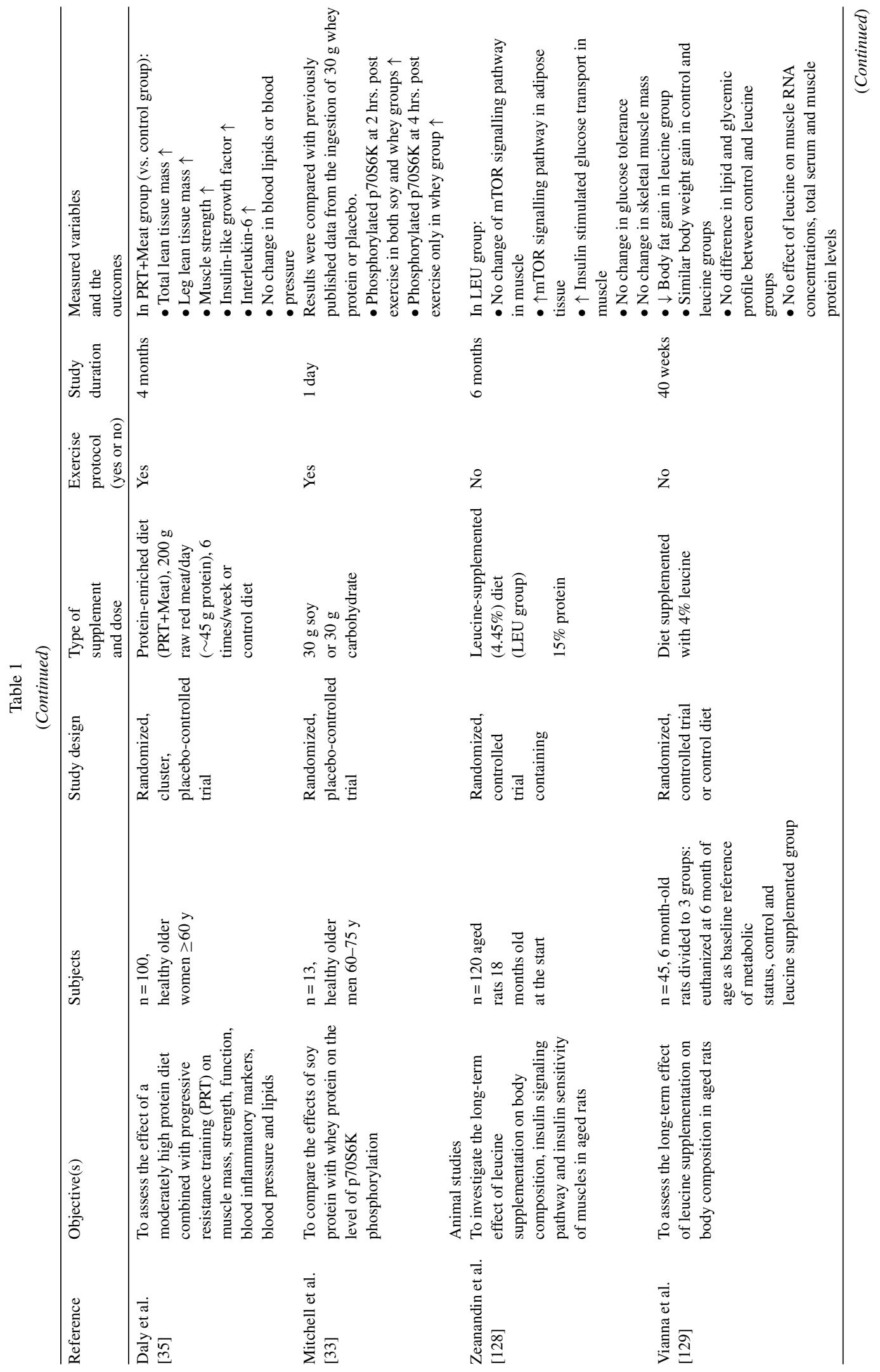




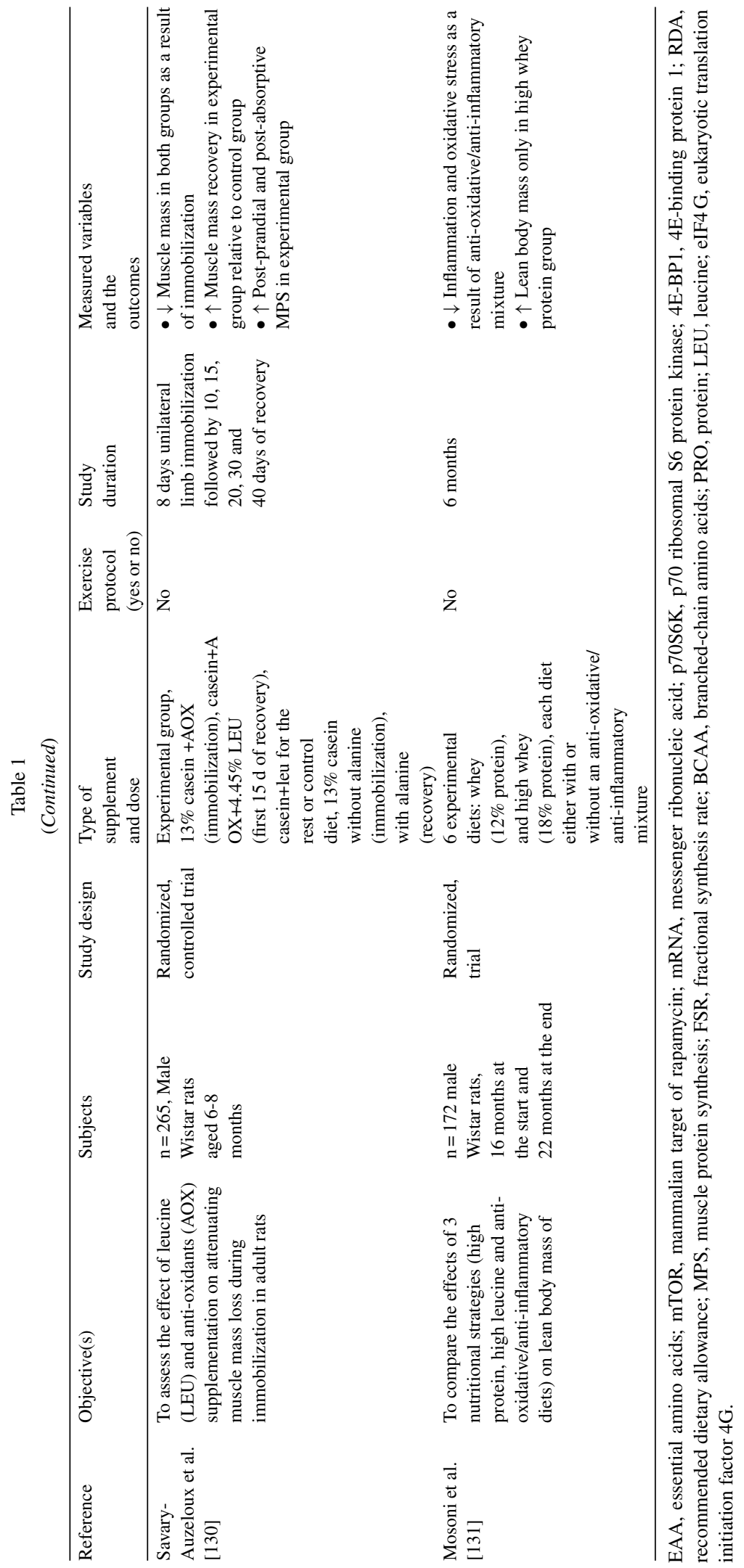




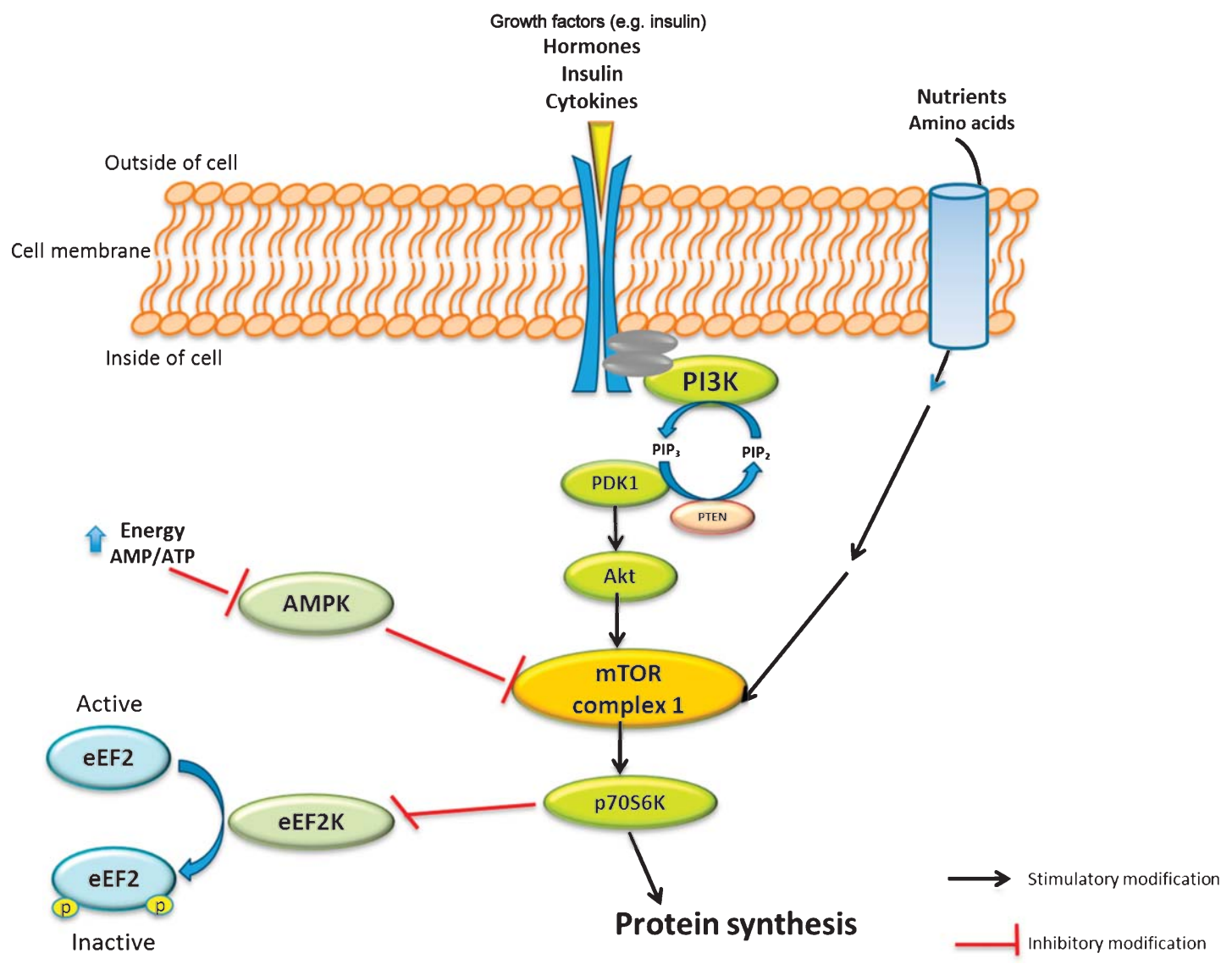

Fig. 2. Simplified view of mammalian target of rapamycin (mTOR) signalling pathway and role of amino acids and leucine in skeletal muscles protein synthesis. mTOR is a conserved serine/threonine kinase involved in many signal transduction pathways within the body, regulating cell growth and homeostasis. The mTOR pathway is activated by insulin, growth factors and amino acids. Activation of mTOR results in the phosphorylation of specific proteins that ultimately phosphorylate and activate p70 ribosomal S6 protein kinase (p70S6K), which triggers a cascade of responses that subsequently results in protein biosynthesis. 5' adenosine monophosphate-activated protein kinase (AMPK) is also a key regulator of cellular energy homeostasis. AMPK can sense the cellular energy level and down-regulate the cellular pathways that consume ATP in case of decreased cell energy content. Eukaryotic elongation factor 2 (eEF2) in its active form results in activation of overall translation elongation in protein synthesis. $\mathrm{PIP}_{2}$ indicates phosphatidylinositol 4,5 bisphosphate; $\mathrm{PIP}_{3}$, phosphatidylinositol $(3,4,5)$-trisphosphate; PTEN, phosphatidylinositol-3,4,5-trisphosphate 3-phosphatase; PDK1, 3-phosphoinositide dependent protein kinase-1; eEF2K, eukaryotic elongation factor 2 kinase; $p$, phosphate; AMP, adenosine monophosphate; ATP, adenosine triphosphate.

stand why different proteins have different effects on mTOR pathway stimulation and the subsequent MPS.

Aleman-Mateo et al. [54] conducted a study with 40 subjects, including men and women over 60 years of age with sarcopenia. They examined the impact of a diet rich in protein from ricotta cheese ( $15.7 \mathrm{~g}$ protein /day, including EAA at $8.6 \mathrm{~g} /$ day) on total appendicular skeletal muscle mass and muscle strength. Unfortunately, the results of the study did not reach statistical significance. In fact, diet rich in ricotta cheese did not have any impact on body composition and strength in elderly with sarcopenia. The authors suggested that perhaps higher amount of dietary protein is needed to elucidate an increase in muscle mass in older adults, i.e. $2 \mathrm{~g} / \mathrm{kg} /$ day, while this study only provided $0.5 \mathrm{~g} / \mathrm{kg} /$ day. Another important factor to consider is that this study used total lean body mass increase as an indicator of effectiveness of protein supplementation. Additional analysis on hand grip strength provided a clear tendency toward significance in the ricotta supplemented group $(P=0.06)$, indicating increased muscle strength. As a final remark, the authors found that some participants experienced difficulty consuming the entire portion of $210 \mathrm{~g}$ of ricotta cheese due to an early satiety. This finding is consistent with previous findings on early satiety in the elderly, especially following a high protein meal [28]. The results of these studies suggest 


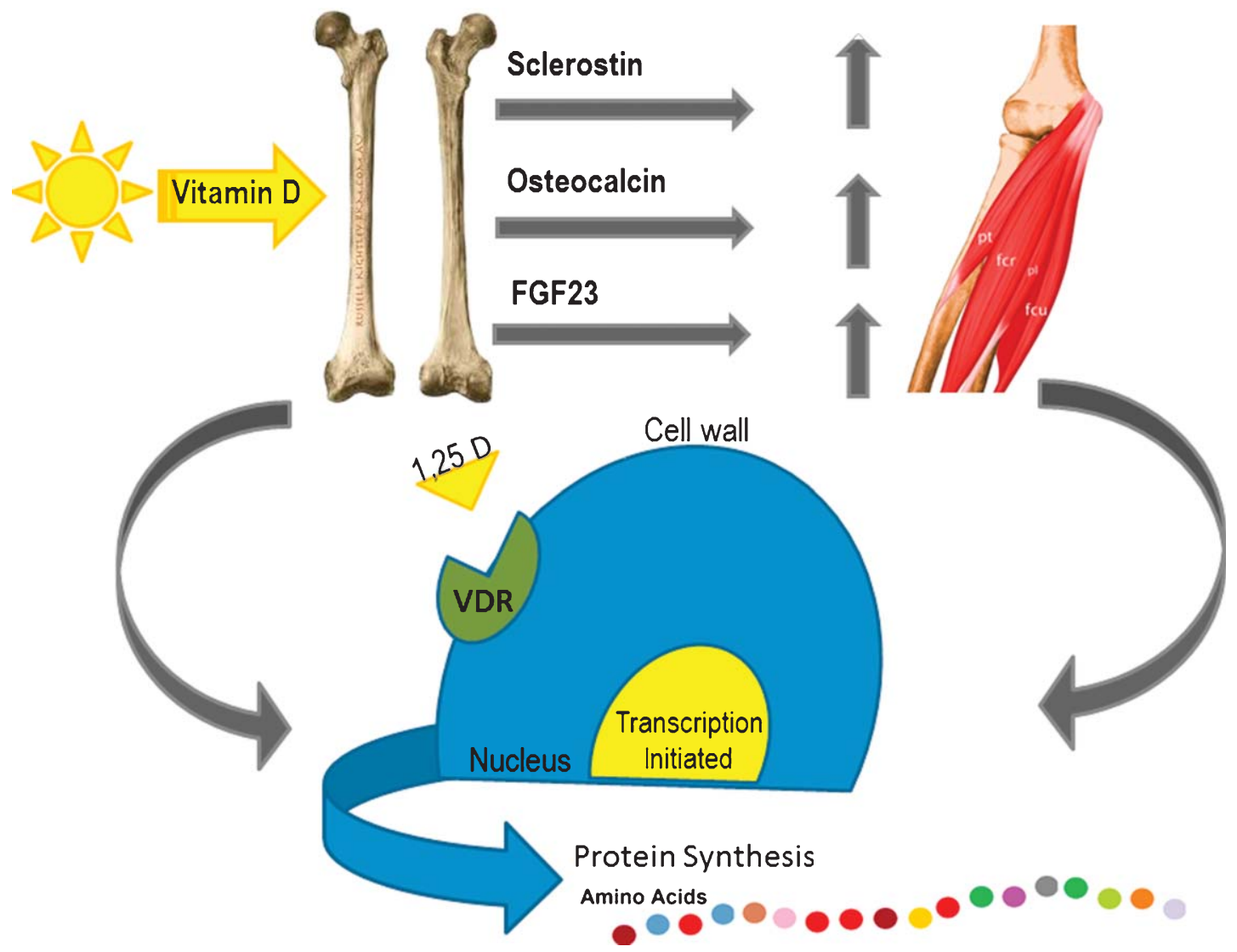

Fig. 3. Muscle-bone cross-talk and vitamin D receptor. Sclerostin is secreted by mature osteocytes in response to vitamin D activation, and it increases bone mass, which in response has a positive effect on certain muscles; however the mechanism is still unknown. Osteocalcin is produced by osteoblasts and regulated by vitamin D. Osteocalcin has a potential effects in muscles by altering mitochondrial function and insulin sensitivity. FGF23 (fibroblast growth factor 23) is a vitamin D responsive hormone produced by bones and has positive effects on cardiac and smooth muscles. Vitamin D Receptor (VDR) can be found in both skeletal and muscle cells, and is activated by 1, 25 Vitamin $\mathrm{D}(1,25 \mathrm{D})$ and contributes to initiation of protein synthesis through bone-muscle cross-talk mechanism [57, 133].

that older adults' digestive capabilities should be taken into account prior to prescribing protein supplementation. Moreover, due to substantial differences between younger adults and older adults' digestive systems, additional research is required in order to select the most efficient way for AA delivery to skeletal tissue in order to achieve the highest impact on MPS. For instance, Milan et al. [55] compared postprandial plasma AA concentrations between a group of older adults $(n=15,60-75 \mathrm{y})$ and younger adults $(n=15,20-25 \mathrm{y})$ following a high protein mixed meal ( $49.8 \mathrm{~g}$ protein). The results of the study showed that older adult digest and absorb protein within a mixed meal slower that younger adults. The authors suggested that delay in AA absorption may delay or suppress protein synthesis in senescent muscle [55]. Therefore, the type of protein and the context of the meal have to be modified to fit the needs of declining digestive functions of older adults. Hence, providing proteins and EAA, especially leucine, in forms of pharmacological supplements may appear as the most feasible way to achieve optimum protein/AA intake in older adults.

The impact of leucine on protein synthesis has been shown in a large body of literature (e.g. Table 1); however, the effective dose by which leucine exerts its role on protein synthesis in the elderly is still not clearly understood. Animal studies indicate that increasing the BCAA-rich whey protein content of the diet from $12 \%$ to $18 \%(12 \%$ whey $=13.8 \mathrm{~g}$ leucine $/ \mathrm{kg}$ diet; $18 \%$ whey $=21.1 \mathrm{~g}$ leucine $/ \mathrm{kg}$ diet) results in attenuating the LBM loss in aged rats. In regards to human studies, most recent research show that administration of $\geq 30-40 \mathrm{~g}$ of whey protein to older adults results in direct stimulation of protein synthesis through mTOR signaling pathway [49]. Although 
these studies (Table 1) provide valuable sources of information on the impacts and effective dose of whey and leucine supplementation in attenuating muscle mass and function losses in the elderly, there is still no agreement in the literature on the optimum level of whey and leucine intakes for treatment of sarcopenia.

In summary, supplementations with protein and AA, especially leucine, are promising strategies targeted at increasing MPS and attenuating agerelated sarcopenia. However the exact effective and safe dosage is still unclear, but current suggestions include: $\geq 30 \mathrm{~g}$ whey protein/day, BCAA-rich protein at $2 \mathrm{~g} / \mathrm{kg} /$ day, or to include whey protein as $18 \%$ of total daily caloric intake (Table 1). In addition to currently obscure protein/AA dosages, the exact route of delivery is questionable given the physiological impairments in the digestive system that occur with aging, which can significantly impact an individual's nutritional status. Therefore, supplementation with high quality protein in its elemental form of AA (especially BCAA) may be a more effective way for optimum MPS stimulation as it by-passes digestive step that appears to be problematic for older adults. Furthermore, on a cautionary note, although higher protein consumption is recommended to attenuate muscle mass loss in sarcopenia, potential adverse effects associated with higher than $0.8 \mathrm{mg} / \mathrm{kg}$ daily protein intake should not be overlooked. For instance, bone disorders and imbalance in calcium homeostasis, renal dysfunction, predisposition to cancer and coronary artery disease are some of the adverse effects mentioned in the literature as consequences of higher than RDA protein consumption [56]. Future studies looking more in depth in the proper dose and timing of administration of protein and AA are required to establish a practical guideline for prevention and management of sarcopenia in the elderly.

\subsection{Vitamin D and calcium}

Increase rates of longevity and adiposity in the general population result in an increased number of musculoskeletal system disorders such as sarcopenia and osteoporosis; both contributing to frailty and increased risk of fractures due to falls in older adults. It is important to mention both muscle and bone diseases as they appear to be linked in both direct function and tissue cross-talk (Fig. 3). Skeletal muscles and bone mass are constantly involved in each other's regulatory pathways, resulting in mutual codependency $[57,58]$. One of these mutual regulators appears to be vitamin D. Research findings showed that vitamin D-responsive hormones that are produced by bone tissue are activated in the presence of vitamin $\mathrm{D}$ and in return have positive effects on MPS. Similar association is seen with vitamin D-responsive factors produced by muscle cells, resulting in positive effect on bone tissue [59]. Therefore, both muscle and bone strengths have to be considered in order to provide optimum treatment and preventative measures for older adults with sarcopenia.

Following the discovery of vitamin D receptors in human muscle cells, it has been identified that vitamin D may induce MPS through direct initiation of transcription and indirect muscle-bone cross talk mechanism [59]. In addition to anabolic effects on muscles, vitamin D may also have a role in moderating inflammation in skeletal muscles. Choi et al. [60] found that vitamin D supplementation in exercised rats decreased inflammatory cytokines, interleukin6 (IL-6) and tumor necrosis factor-alpha (TNF- $\alpha$ ) genes expressions, and increased vitamin $\mathrm{D}$ receptor protein expression in skeletal muscles [60]. A number of studies have concluded that supplementation with vitamin D might improve muscles function and bone strength, thus preventing sarcopenia, frailty, and decreased the risk of falls in the elderly (Table 2). For instance, Mastaglia et al. [61] demonstrated that the strength and function of lower extremities were better preserved with serum hydroxyl-vitamin D level $\geq 20 \mathrm{ng} / \mathrm{ml}$. Indeed, lower vitamin D level in the blood was found to be associated with frailty in older adults [62]. A meta-analysis by Bischoff-Ferrari et al. [63] indicated that vitamin D supplementation at a dose of 700-1000 mg/day in older adults was associated with $19 \%$ reduced risk of falling. In addition, the results from the Fourth Korea National Health and Nutrition Examination Survey (KNHANES IV) in 2009 demonstrated that the serum level of 25hydroxyvitamin $\mathrm{D}$ had positive correlations with total and appendicular lean mass $(R=0.142$ and $R=0.157$, respectively) and negative correlations with total fat mass and appendicular fat mass $(R=-0.188$ and $R=-0.197$, respectively) $(P<0.001$ for all). In fact, sarcopenia in older Koreans was inversely associated with serum vitamin D concentrations [64]. However, further gender-specific analysis of the KNHANES IV data revealed that blood vitamin D levels tended to have a negative association with sarcopenia only in women 50 years of age or older [65]. In contrast, Dupuy et al. [66] conducted a cross-sectional study to determine whether muscle mass was influenced by vitamin D intakes in 1989 community-dwelling older 
French women $(\sim 80 \mathrm{y})$. Low intake of vitamin $\mathrm{D}$ was estimated based on self-reported data and defined at $<70 \mu \mathrm{g} /$ week based on recommended dietary intake (RDI) of vitamin D. Although in this study low muscle mass revealed a significant, positive correlation with obesity, malnutrition and decreased handgrip strength, no association was observed between muscle mass and dietary vitamin D intake [66].

In addition to vitamin D status and intake, the effect of calcium intake on body composition in older adults has been reported in the literature. Data from the KNHANES IV study indicated that the daily calcium intake had a positive $($ rho $=0.281)($ all $P<0.001)$ and negative correlation (rho $=-0.140, P<0.001)$ with skeletal muscle mass and total body fat mass, respectively. Sarcopenic older adults had a lower daily consumption of calcium ( $\leq 278 \mathrm{mg}$ per day) in comparison with participants without sarcopenia [67]. Furthermore, calcium status is influenced by blood vitamin $D$ levels, since 1,25-dihydroxyvitamin $D$, the active form of vitamin $\mathrm{D}$ in the body, binds to vitamin $D$ receptors in the gut and stimulates production of proteins involved in the transluminal transport of calcium in the intestine [68].

In summary, although, the mechanism of musclebone cross-talk is poorly understood, its existence has been prior suspected. Evidences indicate that sarcopenia might be associated with vitamin D deficiency, however this is all based primarily on observational studies as reviewed above and summarized in Table 2. Unfortunately, to date there has been no clear randomized clinical trials showing the benefits of vitamin $\mathrm{D}$ for sarcopenia. Nevertheless, supplementation might be effective for protection against loss of musculoskeletal unit and the subsequent complications, such as falls, which lead to immobility and further decrease in lean muscles mass (i.e. muscle atrophy due to immobility). Evidence suggests that 700-800 international units (IU) of vitamin D in combination with calcium supplement reduces the risk of non-vertebral and hip fractures by approximately 13-26\% [69-71]. Since natural vitamin D requires sun exposure for activation, which may not be feasible in many situations, thus pharmacological supplementation with its active form may be the most efficient way to achieve optimum vitamin $\mathrm{D}$ status for most elders.

\subsection{Antioxidants}

Oxidative stress is a condition resulting from an imbalance between increased free radical production and decreased cell protection mechanism; known as antioxidative capacity. Since free radicals are unstable and have high chemical reactivity, they can wreak havoc on a wide spectrum of biomolecules including DNA, lipids and proteins. Amongst the various free radicals, reactive oxygen species (ROS), which are derived from oxygen, are of utmost importance in biological systems because of their major production site in the cells, i.e. mitochondria [72]. As cellular respiration organelles, mitochondria consume approximately $90 \%$ of the oxygen inside the cells and overproduction of ROS can have destructive effects on mitochondria and cells resulting in mitochondrial mediated apoptosis or cell death [73]. Indeed, the impact of free radicals on aging process was described as early as 1950's by Denham Harman [74] where he enunciated that intracellularly produced free radicals are capable of damaging cell components such as DNA and RNA, leading to aging and aging-associated degenerative alterations [74]. For more information on the generation of ROS and counteraction of cells to oxidative stress during aging the readers are referred to comprehensive literature review such as by Finkel et al. [75].

Among various proposed mechanisms in sarcopenia, impairment in mitochondria and increased oxidative stress are strongly supported by the literature [76-79]. Aging results in reduced content and bioenergetics of mitochondria within skeletal muscle and consequently, oxidative phosphorylation capacity will be diminished in myocytes [76, 78]. Decreased functionality of mitochondria, not only leads to less adenosine triphosphate (ATP) production, but also contributes to greater production and release of ROS from mitochondria [76]. ROS are a major inducer of programmed cell death, apoptosis, and autophagy, resulting in myocyte loss and/or atrophy [76]. Sullivan-Gunn et al. [80] assigned 58 mice into four age categories; 6, 12, 18 and 24 months of age and fed them with standard chow and water under controlled conditions. At 14 months of age, representing middle age, the survival rate of these mice started to drop, whereby $60 \%$ of 18 -month old animals survived, and half of them died in the 24 months of age group. In addition, skeletal muscle mass loss or sarcopenia was observed at 18 months of age. These mice also showed an increase in ROS levels and a decrease in antioxidant enzymes levels in skeletal muscle, indicating a possible role of oxidative damage in sarcopenia [80]. Cross sectional studies in human subjects also demonstrated that older adults with sarcopenia consume below the RDA for 


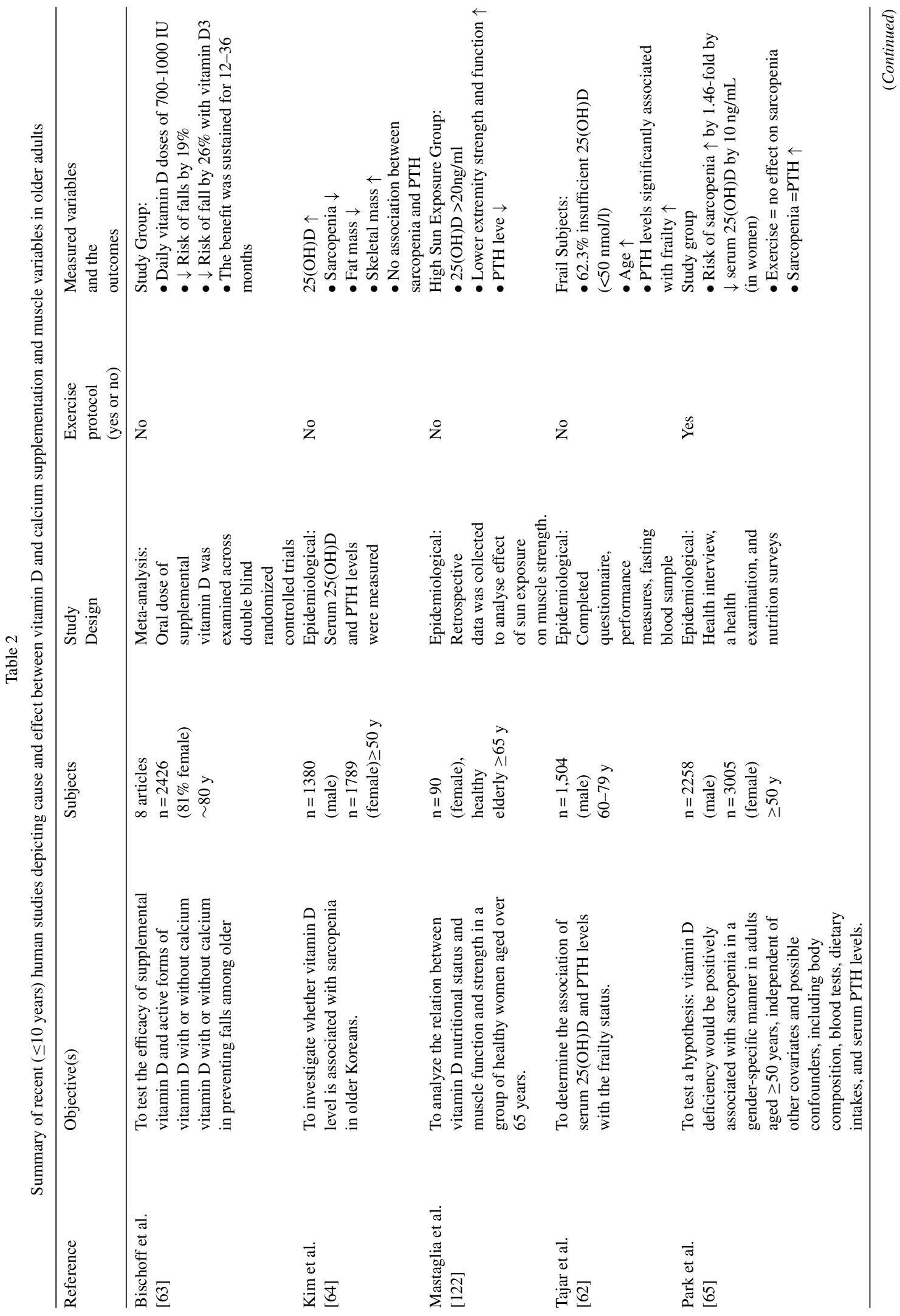




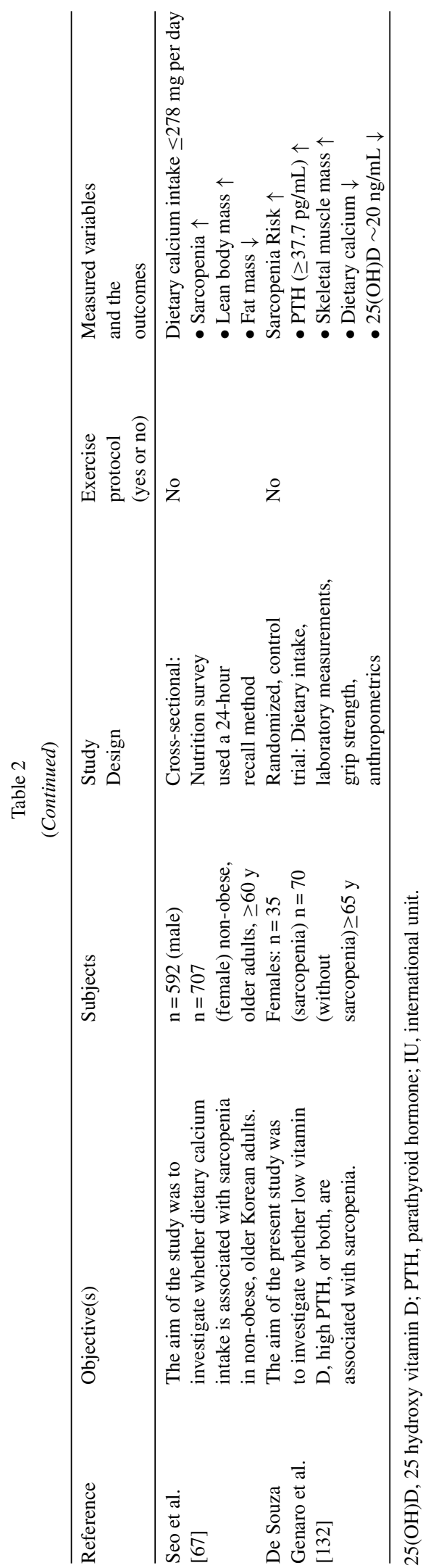


antioxidant nutrients compared to those without sarcopenia [81]. Hence, strategies aiming at reduction of ROS production or detoxifying them may contribute to reversing the devastating consequences of these compounds.

Some researches in the field of sarcopenia have been focused on oxidative stress and treatment strategies using antioxidants. Marzani et al. [82] conducted a study to assess the impact of an antioxidant mixture consisting of rutin, vitamin $\mathrm{E}$, vitamin $\mathrm{A}$, zinc and selenium on anabolic response of aged muscle to stimulatory effect of leucine supplementation. In this study adult ( 8 months, $n=32$ ) and old (20 months, $n=33$ ) male rats were each assigned to one of two experimental protocols to receive either a control diet supplemented (Aox+) or non-supplemented (Aox-) with the antioxidant mixture. After 7 weeks, fast-twitch epitrochlearis muscles were dissected and further incubated in incremental concentrations of leuicne. In Aox-groups, addition of leucine increased protein synthesis in adult rats and to a lesser extent in old rats. No significant alteration was observed in adult rats supplemented with the antioxidants; however, MPS response to leucine was enhanced as a result of antioxidant supplementation in old rats. In this situation, improvement in protein synthesis in old rats was not mediated through activation of p70S6K, but thought to be intervened by a reduction in inflammatory markers, such as plasma $\alpha_{2}$ macroglobulin, which showed a decrease in old rats after antioxidant supplementation [82]. Although, the effect of antioxidants on MPS (activation of elements of protein synthesis pathway) and inflammatory biomarkers were assessed in this study, the exact mechanism by which antioxidants induce their impacts on the muscle cells was not investigated. In addition, alteration in muscle mass and/or function in aging due to antioxidant supplementation are also areas that require further examination.

Animal and human bodies possess endogenous antioxidant compounds and enzymes, e.g. glutathione, superoxide dismutase and catalase, to defend the body against oxidative attack [83]. In addition, antioxidative capacity of various exogenous dietary sources such as vitamin C [84], vitamin E [85], carotenoids [86] and polyphenols [87] have long been reviewed in the literature showing that they can compensate the body's antioxidant requirements [88, 89]. The ability of antioxidants to scavenge ROS prevents further damage to the cell structures notably mitochondria [90]. Ryan et al. [21] supplemented 28 aged rats either with or without vitamin C and $\mathrm{E}$ and demonstrated that these vitamins lowered the indices of aging-associated oxidative damage. Similarly, Bobeuf and colleagues [91] demonstrated that supplementation of older rats with vitamin $\mathrm{C}$ (l-ascorbic acid, $2 \%$ by weight) and $\mathrm{E}$ (dl-alphatocopheryl acetate, $30000 \mathrm{mg} / \mathrm{kg}$ ) combined with resistance exercise for 4.5 weeks increased appendicular fat free mass after 6 months of study period; however these researchers could not detect any significant change in oxidative damage parameters.

Carotenoids; organic pigments abundantly found in plants and vegetables, are supposed to have an inverse association with muscle dysfunction and disability in older adults [92]. Follow-up study of 628 elderly men and women aged 65 and older for 6 years revealed that lower plasma concentrations of carotenoids were accompanied by greater risk of poor hip, knee and grip muscle strength [92]. Similar results regarding the relationship between plasma carotenoid levels and hip, knee and grip strengths were also attained from elderly women who participated in a cross-sectional study; in fact, higher carotenoids levels were correlated with better strength measures [93]. These observational studies suggest that carotenoids may have protective effect against aging-associated muscle function loss. However, further clinical controlled studies are required to demonstrate the beneficial roles of carotenoids in attenuating sarcopenia in older adults.

In addition to carotenoids, vitamins $\mathrm{C}$ and $\mathrm{E}$, the antioxidant effect of other dietary nutrients such as resveratrol, has been investigated in the literature. Resveratrol is a member of the polyphenolic compounds, which are known for their antioxidative and anti-inflammatory properties. Skin of red grapes is the major natural source of resveratrol, but it can also be found in peanuts and berries [94]. Resveratrol is present in plants and fruits in a small amount, therefore in order to reach the pharmacological doses effective for health related conditions, resveratrol is extracted from Polygonum cuspidatum (knotweed) as a nutritional supplement [95]. Investigators claimed that polyphenols and resveratrol have beneficial preventive and therapeutic effects on a number of health conditions such as obesity, diabetes, hypercholesterolemia, cancer, Alzheimer's disease and aging associated disorders [94]. In an in vitro study with C2C12 myoblast cells, resveratrol hindered increased production of ROS induced by transforming growth factor- $\beta 1$ (TGF- $\beta 1$ ), a cytokine promoting fibrosis in muscles [96]. Other in vitro studies also demonstrated that resveratrol is capable of reversing muscle 
mass loss induced by inflammation, mainly the pro-inflammatory cytokine TNF- $\alpha$, through regulation of $\mathrm{Akt} / \mathrm{mTOR} / \mathrm{FoxO} 1$ signaling pathway, which enhances MPS required for muscle structure and function. Akt (protein kinase B) is a kinase capable of controlling both MPS, via phosphorylating and activating of mTOR, and MPD, by inactivating of transcription factor Forkhead Box O1 [97]. In addition, intra-gastric administration of resveratrol with a dose of $100 \mathrm{mg} / \mathrm{kg} /$ day to 8 month-old rats for 12 weeks decreased ROS level in subsarcolemmal and intermyofibrillar mitochondria and increased antioxidative capacity as measured by total superoxide dismutase (SOD), glutathione peroxidase and catalase enzymes activity levels in tibialis anterior muscle [98]. Nevertheless, there are some discrepancies in the literature regarding antioxidative effect of resveratrol. When Barger et al. [99] supplemented 14 month-old male mice with $4.9 \mathrm{mg} / \mathrm{kg} /$ day for approximately 16 months, markers of oxidative damage to DNA and RNA [8-hydroxy-29-deoxyguanosine (8-OHdG) and 8-hydroxyguanosine (8-OHG)] and the marker of lipid peroxidation (F2-isoprostanes) in soleus and extensor digitorum longus muscles did not change significantly as a consequence of resveratrol supplementation [99]. Although the duration of this study was long enough to give rise to any beneficial effects of resveratrol, the provided dosage might not be sufficient to initiate the antioxidative impacts of resveratrol. Ingestion of higher doses, $12.5 \mathrm{mg} / \mathrm{kg} /$ day, of resveratrol for 21 days in older rats (34 month-old), who received hind limb suspension for 14 days during the course of the study, was shown to affect oxidative stress markers by increasing catalase and manganese SOD (MnSOD) activities and decreasing lipid peroxidation and hydrogen peroxide contents in gastrocnemius muscle [100]. Although Jackson et al. [100] examined the gastrocnemius muscle as a whole, without having concern about different fiber types, a later study by the same research group [101] demonstrated that slow-twitch, gycolytic gastrocnemius muscle fibers are more responsive to resveratrol than fast-twitch, oxidative fibers in gastrocnemius muscle. Supplementing old (27 month-old) male rats with $50 \mathrm{mg} / \mathrm{kg} /$ day resveratrol for 6 weeks enhanced sirtuin 1 (SIRT1), a histone residue deacetylase which is supposed to be associated with increased longevity and aging suppression [102], in slow-twitch gastrocnemius muscle fibers. However, the resveratrol supplementation regimen did not have any impact on oxidative stress markers and muscle mass [101]. Nonetheless, the increase in
SIRT1 activity was also shown in a study conducted by Zheng et al. [98] that has been discussed earlier in this section.

To assess the effect of resveratrol in agingassociated muscle mass loss, Bennett et al. [106] applied hind limb suspension in combination with $125 \mathrm{mg} / \mathrm{kg} / \mathrm{day}$ resveratrol supplementation for 14 days in 32 month-old male aged rats. Although resveratrol was not effective in preventing the plantaris muscle mass loss during loading period, it improved type II, fast-twitch muscle fiber size and muscle mass during the recovery period. Wang et al. [103] used an interleukin-10 (IL-10), an antiinflammatory cytokine, knockout mouse model to investigate the effect of the grape seed extract (consisting of $>95 \%$ flavonols), which is a by-product of wineries and grape juice producing industries. This mouse model exhibit chronic inflammation, accelerated muscle mass loss and frailty. Supplementing these animals with resveratrol for 12 weeks ameliorated tibialis anterior muscle mass loss, reduced protein degradation and rectified the inhibition of anabolic signaling pathway [103]. Although resveratrol revealed a protective effect against oxidative damage by reducing autophagy and apoptosis, some researchers claim that it was not able to attenuate muscle mass loss in sarcopenia [107]. In fact 10-month resveratrol supplementation of middle-aged mice was effective in preserving the fast-twitch muscle fiber function and age related oxidative stress, however it could not prevent muscle mass loss in these animals [107]. Although the result of this study in regard to the effect of resveratrol on muscle mass was in agreement with Joseph et al. [101], different fiber types were responsive to the beneficial effects of resveratrol supplementation in these studies. Therefore, it is not clear whether the effect of resveratrol is fiber-specific and if so, which fiber types are more responsive to this treatment. More research is required to elucidate the mechanism and role of resveratrol in attenuating muscle mass and function loss in elderly.

Overall, antioxidants provide a promising venue for combating muscle mass loss in sarcopenia, since increased oxidative stress is an inseparable part of this disorder and many other aging-associated conditions. Antioxidants are found in plenty of foods, primarily in vegetables and fruits. It is well known that the bioavailability of antioxidants from vegetable and fruit sources is optimum to maintain defenses against oxidative stress in healthy young people. As stated earlier in this review, a number of digestive misalignments prevent older adults from 
optimal nutrient utilization. However, in the case of antioxidants, it appears that older adults benefit from dietary vegetable and fruit consumptions as much as do younger adults. For instance, Kim, et al. [4] performed a cross-sectional examination of the KNHANES IV study, comprised of 823 men and 1,089 community-dwelling women aged $\geq 65$ years, to assess the relationships between vegetables and fruits consumptions and the effects on sarcopenia. The results of the study showed that after adjustment for all covariates, higher frequency of vegetables, fruits and combined fruits and vegetables consumption was accompanied by lower risk of sarcopenia among older men. For women, the risk of sarcopenia decreased as the number of servings of fruit per day increased.

Although, without a doubt, dietary antioxidant intake is superior to synthetic antioxidants, some older adults might be forced to resort to synthetic supplementation. A number of studies indicated that there is a difference in bioavailability between different synthetic antioxidants. For instance, pharmacokinetic studies indicate that carotenoids are less bioavailable in the form of a supplement, while synthetic and food-derived vitamin $\mathrm{C}$ is relatively comparable [108, 109]. Therefore, unless indicated otherwise, it appears prudent to use dietary therapy rich in vegetables and fruits in efforts to combat sarcopenia-induced oxidative stress. However, given the anorexia of aging, more research is needed to identify if some older adults might be experiencing significant difficulty consuming sufficient amounts of vegetables and fruits to obtain their beneficial health effects. Also, it will be prudent to identify if preparatory techniques such as mincing/puree could help to increase vegetables and fruit consumption in the elderly. Furthermore, more research is required to determine if supplementation with antioxidants could be beneficial adjuvant therapy to AA and proteins for enhancing or maintaining muscle mass and function in aging populations.

\subsection{Omega-3 fatty acids}

The etiology of sarcopenia is still not clearly understood, however a number of factors have been proposed as potential contributors to sarcopenia. One of these possible mechanisms is the increased circulating cytokines and pro-inflammatory markers (Fig. 1), which are associated with the aging process $[16,110,111]$. Dysregulation of inflammatory pathways during aging is suggested to play a major role in the pathogenesis of various age-related disorders such as cardiovascular events, Alzheimer's disease and sarcopenia. In fact, elevated levels of pro-inflammatory cytokines like IL-6, interleukin- $1 \beta$ (IL-1 $\beta$ ) and TNF- $\alpha$, as well as decreased antiinflammatory cytokines, as a consequence of aging initiates a cascade of events, ultimately resulting in impaired response of skeletal muscle to anabolic signals [110]. In younger muscles, anabolic stimuli affects MPS, outpacing it from MPD and subsequently resulting in increased muscle mass [112]. Nevertheless, anabolic resistance in aged muscle deranges this equilibrium between MPS and MPD, which leads to gradual loss of muscle mass [112]. It has been shown that the presence of even low-grade inflammation in aged rats results in irresponsiveness of post-prandial MPS to nutritional stimuli, whereas control non-inflamed counterpart rats have increased MPS after food intake [113]. In addition, longterm prevention of inflammation with a non-steroidal anti-inflammatory drug (e.g., ibuprofen) reduces the inflammatory biomarkers and cytokines levels such as fibrinogen, $\alpha_{2}$-macroglobuline, IL- 6 and IL-1 $\beta$ leading to enhanced MPS and diminished MPD in aged rats [114].

Omega-3 fatty acids are polyunsaturated fatty acids (PUFA) that are essential nutrients with antiinflammatory properties. Oily fish like salmon is a common source of omega-3 fatty acids, while plant oils such as canola and flaxseed oil also contain omega-3 fatty acids [115]. A large body of evidence supports the beneficial effects of these omega-3 fatty acids in various clinical conditions including cancers, cardiovascular diseases, inflammatory disorders and cognitive impairments [116]. Omega-3 fatty acids exert their anti-inflammatory activity through several mechanisms including reduced leukocyte chemotaxis, decreased production of eicosanoids from arachidonic acid, and reduced T-cell reactivity [116]. Therefore, it has been speculated that older adults with sarcopenia would also benefit from more omega-3 fatty acids consumption, since inflammation is one of the underlying pathophysiological events during the disease process $[15,111]$. Furthermore, it has been shown that the anabolic response of skeletal muscle to AA administration may be enhanced by combining with omega-3 fatty acids supplementation [15, 117]. Smith et al. [15] conducted a study with 16 healthy older adults, aged 65 years or more, to investigate whether supplementation with omega-3 fatty acids for 8 weeks had 
any impact on the rate of MPS and anabolic signaling. In this randomized controlled trial, subjects were assigned to either omega-3 fatty acid or corn oil (control) group. The measurements were done at basal, post-absorptive conditions and after administration of hyperaminoacidemic-hyperinsulinemic clamp, before and after supplementation with omega3 fatty acids and corn oil. The results of this study revealed that hyperaminoacidemic-hyperinsulinemic clamp induced a rise in MPS in both groups $(P<0.01)$; however only omega-3 fatty acids could augment this increase $(P=0.01)$. Similar positive effects on muscle mTORC1 and p70S6K activity, which are involved in anabolic signaling pathways in muscles, were also observed in the omega-3 fatty acids supplemented group $(P=0.07$ and $P<0.05$, respectively). Overall, the data from this trial suggested a possible role of omega-3 fatty acids in overcoming the metabolic resistance in skeletal muscle and attenuating muscle mass loss in older adults [15]. The effect of omega-3 fatty acids on muscles has also been studied beyond the scope of increasing MPS and muscle mass. In fact, consumptions of omega-3 fatty acids have been shown to improve muscle function by enhancing muscle strength and performance [117-120]. Another study by Smith et al. [117] demonstrated that supplementation with omega-3 fatty acids [four $1 \mathrm{~g}$ pills per day, providing 1.86 g eicosapentaenoic acid (EPA; 20:5n-3)/day and $1.5 \mathrm{~g}$ docosahexaenoic acid (DHA; 22:6n-3)/day] for 6 months not only increases thigh muscle volume, but also enhances hand grip strength and average isokinetic power [117]. Similarly, dietary assessments of nearly 3000 elderly men and women have shown positive associations between fatty fish consumption and grip strength in both genders [118].

As discussed earlier, one of the hypothesis behind the beneficial effects of omega-3 fatty acids on improvement of muscle mass (size) and function is primarily thought to be due to reduced inflammatory processes and its associated biomarkers [110]. To test this theory Cornish et al. [111] recruited 51 older adults in a randomized double-blind trial. Subjects were almost equally assigned to one of two groups to receive either $14 \mathrm{~g}$ alpha-linolenic acid/day (ALA, an 18 carbon essential omega-3 fatty acid, i.e., 18:3n-3) through $30 \mathrm{ml}$ of flax seed oil or iso-caloric corn oil (placebo). At the same time, both groups were completing a resistancetraining program. After 12 weeks, male subjects in the ALA-supplemented group demonstrated a significant reduction in blood concentration of IL-6 (62 $\pm 36 \%$ decrease; $P=0.003)$. However, male subjects in the placebo group and women in both ALA and placebo group did not show any significant changes in IL-6 concentrations. Likewise, while the trend of change in blood concentration of TNF- $\alpha$ was parallel to IL-6, it failed to reveal any statistical significant difference. In addition, resistance training with or without ALA supplements was effective in enhancing muscle thickness $(P=0.05)$, muscle strength $(P=0.006)$ and $\operatorname{LBM}(P<0.01)$, and ALA had showed minimal effects on these parameters. The researchers speculated that the lack or minimum effect of omega-3 fatty acid in this study in enhancing muscle mass may be due to the supplemented form, i.e. flax seed oil versus omega-3 in fish oil [111]. That is, flax seed fatty acids $(18: 3 n-3)$ have to undergo desaturation and elongation reactions to produce EPA (20:5n-3) and DHA $(22: 6 n-3)$, which are already present as the primary omega-3 fatty acids in fish oil [121]. Nevertheless, the potential influence of ALA in lowering plasma IL-6 level in older men is promising for future directions toward the treatment of sarcopenia.

Although consumption of fatty fish and plantbased rich sources appears to be reasonable strategies to achieve adequate omega- 3 fatty acids supplementation, research shows that dietary intake of omega- 3 fatty acids in older adults might be insufficient [115]. Therefore, more research is needed to identify barriers preventing older adults from consuming substantial amounts of omega-3 fatty acids from natural sources. Currently, research shows that consumption of $\geq 1.27 \mathrm{~g} /$ day of omega- 3 fatty acids or $\geq 1$ servings of fatty fish per week is associated with higher bone mineral density, greater leg strength and lower time to rise from a chair [115]. Thus, dietary and/or supplemental forms of omega-3 fatty acids both appear as useful and effective ways to improve sarcopeniarelated functional impairments in older adults.

\section{Conclusion}

With the rapid growth in the older adult population, sarcopenia is becoming increasingly prominent as a major health problem, contributing to enhanced frailty and debility. Sarcopenia is a severe debilitating condition with a progressive, frequently irreversible nature. A broad range of investigations is required to understand the pathophysiology of this condition in order to find feasible treatment approaches to combat this age-related disorder. Without a doubt, nutrition plays a central role in attenuating muscle 
mass loss in aging population, with some research to date highlighting the roles of proteins and AA, vitamin $\mathrm{D}$ and calcium, antioxidants and omega-3 fatty acids as some of the most promising nutritional strategies to manage sarcopenia. Looking in depth into the mechanism of action of each nutrient can assist researchers in perceiving the cellular targets, possible interactions, synergistic or antagonistic effects of these nutritious elements. To optimize these nutritional strategies, one should also consider the physiological impairments that seemed to accompany aging such as as early onset of satiety in combination with prolonged chewing might significantly diminish the amount of dietary nutrients consumed by an elderly person. Therefore, in efforts to prevent the onset of the sarcopenia or attenuate its progression, early continued nutritional therapies should be considered for older adults in forms of both pharmacological and dietary interventions with reflection of both mechanistic and physiologic aspect of each and all nutrients. There is also a paucity of information regarding combination nutritional therapies which includes protein/AA, vitamin D and calcium, omega-3 fatty acids and antioxidants. Overall, more research is needed to establish exact age of supplementation initiation, exact amounts for the nutrients of interest, combinations of nutrients, and optimum form and schedule of administration.

\section{Acknowledgments}

F.F., V.S. and S.B.M. wrote and approved the final manuscript.

\section{Conflict of interest}

The authors declare no conflicts of interest.

\section{References}

[1] Rosenberg IH. Summary comments. The American Journal of Clinical Nutrition. 1989;50(5 SUPPL.):1231-3.

[2] Rosenberg IH. Sarcopenia: origins and clinical relevance. J Nutr. 1997;127(5 Suppl):990S-1S.

[3] Cederholm T, Morley JE. Sarcopenia: The new definitions. Current opinion in clinical nutrition and metabolic care. 2015;18(1):1-4. Epub 2014/09/11.

[4] Kim J, Lee Y, Kye S, Chung YS, Kim KM. Association of vegetables and fruits consumption with sarcopenia in older adults: The Fourth Korea National Health and Nutrition Examination Survey. Age and Ageing. 2014;27:27.
[5] Walston JD. Sarcopenia in older adults. Current opinion in rheumatology. 2012;24(6):623-7. Epub 2012/09/08.

[6] Hida T, Harada A, Imagama S, Ishiguro N. Managing sarcopenia and its related-fractures to improve quality of life in geriatric populations. Aging Dis. 2013;5(4):226-37.

[7] Ziegler CC, Sidani MA. Diets for successful aging. Clinics in Geriatric Medicine. 2011;27(4):577-89. Epub 2011/11/09.

[8] Chung JY, Kang HT, Lee DC, Lee HR, Lee YJ. Body composition and its association with cardiometabolic risk factors in the elderly: a focus on sarcopenic obesity. Arch Gerontol Geriatr. 2013;56(1):270-8.

[9] Lee S, Kim TN, Kim SH. Sarcopenic obesity is more closely associated with knee osteoarthritis than is nonsarcopenic obesity: a cross-sectional study. Arthritis Rheum. 2012;64(12):3947-54.

[10] Defina PA, Moser RS, Glenn M, Lichtenstein JD, Fellus J. Alzheimer's Disease Clinical and Research Update for Health Care Practitioners. Journal of Aging Research. 2013;2013:207178. Epub 2013/10/02.

[11] Moon SS. Low skeletal muscle mass is associated with insulin resistance, diabetes, and metabolic syndrome in the Korean population: The Korea National Health and Nutrition Examination Survey (KNHANES) 2009-2010. Endocr J. 2014;61(1):61-70.

[12] Rosenberg IH. Sarcopenia: Origins and clinical relevance. Clin Geriatr Med. 2011;27(3):337-9.

[13] Brotto M, Abreu EL. Sarcopenia: Pharmacology of today and tomorrow. The Journal of Pharmacology and Experimental Therapeutics. 2012;343(3):540-6. Epub 2012/ $08 / 30$.

[14] Malafarina V, Uriz-Otano F, Iniesta R, Gil-Guerrero L. Effectiveness of nutritional supplementation on muscle mass in treatment of sarcopenia in old age: A systematic review. Journal of the American Medical Directors Association. 2013;14(1):10-7. Epub 2012/09/18.

[15] Smith GI, Atherton P, Reeds DN, Mohammed BS, Rankin D, Rennie MJ, Mittendorfer B. Dietary omega-3 fatty acid supplementation increases the rate of muscle protein synthesis in older adults: a randomized controlled trial. Am J Clin Nutr. 2011;93(2):402-12. Epub 2010/12/17.

[16] Solerte SB, Gazzaruso C, Bonacasa R, Rondanelli M, Zamboni M, Basso C, Locatelli E, Schifino N, Giustina A, Fioravanti M. Nutritional supplements with oral amino acid mixtures increases whole-body lean mass and insulin sensitivity in elderly subjects with sarcopenia. The American Journal of Cardiology. 2008;101(11a):69e-77e. Epub 2008/07/02.

[17] Mason C, Xiao L, Imayama I, Duggan CR, Foster-Schubert KE, Kong A, Campbell KL, Wang CY, Villasenor A, Neuhouser ML, Alfano CM, Blackburn GL, McTiernan A. Influence of diet, exercise, and serum vitamin $d$ on sarcopenia in postmenopausal women. Med Sci Sports Exerc. 2013;45(4):607-14. Epub 2012/11/30.

[18] Sinha-Hikim I, Sinha-Hikim AP, Parveen M, Shen R, Goswami R, Tran P, Crum A, Norris KC. Long-term supplementation with a cystine-based antioxidant delays loss of muscle mass in aging. J Gerontol A Biol Sci Med Sci. 2013;68(7):749-59. Epub 2013/03/06.

[19] Donini LM, Poggiogalle E, Piredda M, Pinto A, Barbagallo M, Cucinotta D, Sergi G. Anorexia and eating patterns in the elderly. PLoS One. 2013;8(5):e63539. Epub 2013/05/10. 
[20] Dillon EL, Sheffield-Moore M, Paddon-Jones D, Gilkison C, Sanford AP, Casperson SL, Jiang J, Chinkes DL, Urban RJ. Amino acid supplementation increases lean body mass, basal muscle protein synthesis, and insulin-like growth factor-I expression in older women. J Clin Endocrinol Metab. 2009;94(5):1630-7. Epub 2009/02/12.

[21] Ryan MJ, Dudash HJ, Docherty M, Geronilla KB, Baker BA, Haff GG, Cutlip RG, Alway SE. Vitamin E and C supplementation reduces oxidative stress, improves antioxidant enzymes and positive muscle work in chronically loaded muscles of aged rats. Experimental Gerontology. 2010;45(11):882-95. Epub 2010/08/14

[22] Walrand S, Guillet C, Salles J, Cano N, Boirie Y. Physiopathological mechanism of sarcopenia. Clin Geriatr Med. 2011;27(3):365-85.

[23] Paddon-Jones D, Campbell WW, Jacques PF, Kritchevsky SB, Moore LL, Rodriguez NR, van Loon LJ. Protein and healthy aging. Am J Clin Nutr. 2015;29.

[24] Keller H, Beck AM, Namasivayam A. Improving food and fluid intake for older adults living in long-term care: a research agenda. Journal of the American Medical Directors Association. 2015;16(2):93-100.

[25] Saffrey MJ. Aging of the mammalian gastrointestinal tract: A complex organ system. Age. 2014;36(3):013-9603.

[26] Saarela RK, Lindroos E, Soini H, Hiltunen K, Muurinen S, Suominen MH, Pitkala KH. Dentition, nutritional status and adequacy of dietary intake among older residents in assisted living facilities. Gerodontology. 2014;28(10):12144.

[27] Hiramatsu T, Kataoka H, Osaki M, Hagino H. Effect of aging on oral and swallowing function after meal consumption. Clin Interv Aging. 2015;10:229-35.

[28] Soenen S, Rayner CK, Horowitz M, Jones KL. Gastric Emptying in the Elderly. Clinics in Geriatric Medicine. 2015;31(3):339-53. Epub 2015/05/11.

[29] Pennings B, Groen B, de Lange A, Gijsen AP, Zorenc AH, Senden JM, van Loon LJ. Amino acid absorption and subsequent muscle protein accretion following graded intakes of whey protein in elderly men. Am J Physiol Endocrinol Metab. 2012;302(8):14.

[30] Wall BT, Dirks ML, van Loon LJ. Skeletal muscle atrophy during short-term disuse: implications for age-related sarcopenia. Ageing research reviews. 2013;12(4):898-906. Epub 2013/08/21.

[31] Moore DR, Tang JE, Burd NA, Rerecich T, Tarnopolsky MA, Phillips SM. Differential stimulation of myofibrillar and sarcoplasmic protein synthesis with protein ingestion at rest and after resistance exercise. The Journal of Physiology. 2009;587(Pt 4):897-904.

[32] Houston DK, Nicklas BJ, Ding J, Harris TB, Tylavsky FA, Newman AB, Lee JS, Sahyoun NR, Visser M, Kritchevsky SB. Dietary protein intake is associated with lean mass change in older, community-dwelling adults: the Health, Aging, and Body Composition (Health ABC) Study. Am J Clin Nutr. 2008;87(1):150-5. Epub 2008/01/08.

[33] Mitchell CJ, Della Gatta PA, Petersen AC, Cameron-Smith $\mathrm{D}$, Markworth JF. Soy protein ingestion results in less prolonged p70S6 kinase phosphorylation compared to whey protein after resistance exercise in older men. Journal of the International Society of Sports Nutrition. 2015;12(6): 015-0070.

[34] Luiking YC, Deutz NE, Memelink RG, Verlaan S, Wolfe RR. Postprandial muscle protein synthesis is higher after a high whey protein, leucine-enriched supplement than after a dairy-like product in healthy older people: a randomized controlled trial. Nutr J. 2014;13(9):1475-2891.

[35] Daly RM, O'Connell SL, Mundell NL, Grimes CA, Dunstan DW, Nowson CA. Protein-enriched diet, with the use of lean red meat, combined with progressive resistance training enhances lean tissue mass and muscle strength and reduces circulating IL-6 concentrations in elderly women: a cluster randomized controlled trial. Am J Clin Nutr. 2014;99(4):899-910.

[36] Wu G. Amino acids: metabolism, functions, and nutrition. Amino Acids. 2009;37(1):1-17.

[37] Dillon EL. Nutritionally essential amino acids and metabolic signaling in aging. Amino Acids. 2013;45(3): 431-41.

[38] Wang X, Wei H, Cao J, Li Z, He P. Metabolomics analysis of muscle from piglets fed low protein diets supplemented with branched chain amino acids using HPLC-high resolution MS. Electrophoresis. 2015;28(10):201500007.

[39] Bajotto G, Sato Y, Kitaura Y, Shimomura Y. Effect of branched-chain amino acid supplementation during unloading on regulatory components of protein synthesis in atrophied soleus muscles. Eur J Appl Physiol. 2011;111(8):1815-28.

[40] Layman DK, Walker DA. Potential importance of leucine in treatment of obesity and the metabolic syndrome. J Nutr. 2006;136(1 Suppl):319S-23S.

[41] Layman DK. The role of leucine in weight loss diets and glucose homeostasis. J Nutr. 2003;133(1):261S-7S.

[42] Casperson SL, Sheffield-Moore M, Hewlings SJ, PaddonJones D. Leucine supplementation chronically improves muscle protein synthesis in older adults consuming the RDA for protein. Clin Nutr. 2012;31(4):512-9.

[43] Faure C, Raynaud-Simon A, Ferry A, Dauge V, Cynober L, Aussel C, Moinard C. Leucine and citrulline modulate muscle function in malnourished aged rats. Amino Acids. 2012;42(4):1425-33.

[44] Tang H, Inoki K, Lee M, Wright E, Khuong A, Sugiarto S, Garner M, Paik J, DePinho RA, Goldman D, Guan KL, Shrager JB. mTORC1 promotes denervationinduced muscle atrophy through a mechanism involving the activation of FoxO and E3 ubiquitin ligases. Sci Signal. 2014;7(314):2004809.

[45] Steiner JL, Lang CH. Dysregulation of skeletal muscle protein metabolism by alcohol: Am J Physiol Endocrinol Metab. 2015 May 1;308(9):E699-E712. doi: 10.1152/ajpendo.00006.2015. Epub 2015 Mar 10.

[46] Tramutola A, Triplett J, Domenico FD, Niedowicz DM, Murphy MP, Coccia R, Perluigi M, Butterfield DA. Alteration of mTOR signaling occurs early in the progression of Alzheimer disease: analysis of brain from subjects with Preclinical AD, amnestic mild cognitive impairment and late-stage AD. J Neurochem. 2015;27(10):13037.

[47] Ruggero D, Montanaro L, Ma L, Xu W, Londei P, Cordon-Cardo C, Pandolfi PP. The translation factor eIF$4 \mathrm{E}$ promotes tumor formation and cooperates with c-Myc in lymphomagenesis. Nat Med. 2004;10(5):484-6.

[48] Nacarelli T, Azar A, Sell C. Aberrant mTOR activation in senescence and aging: A mitochondrial stress response? Experimental gerontology. 2014;6(14):00301-5.

[49] D'Souza RF, Marworth JF, Figueiredo VC, Della Gatta PA, Petersen AC, Mitchell CJ, Cameron-Smith D. 
Dose-dependent increases in p70S6K phosphorylation and intramuscular branched-chain amino acids in older men following resistance exercise and protein intake. Physiol Rep. 2014;2(8):1.

[50] Mouisel E, Vignaud A, Hourde C, Butler-Browne G, Ferry A. Muscle weakness and atrophy are associated with decreased regenerative capacity and changes in mTOR signaling in skeletal muscles of venerable (18-24-month-old) dystrophic mdx mice. Muscle Nerve. 2010;41(6):809-18.

[51] Sandri M, Coletto L, Grumati P, Bonaldo P. Misregulation of autophagy and protein degradation systems in myopathies and muscular dystrophies. J Cell Sci. 2013;126(Pt 23):5325-33.

[52] Sandri M, Barberi L, Bijlsma AY, Blaauw B, Dyar KA, Milan G, Mammucari C, Meskers CG, Pallafacchina G, Paoli A, Pion D, Roceri M, Romanello V, Serrano AL, Toniolo L, Larsson L, Maier AB, Munoz-Canoves P, Musaro A, Pende M, Reggiani C, Rizzuto R, Schiaffino S. Signalling pathways regulating muscle mass in ageing skeletal muscle: The role of the IGF1-Akt-mTOR-FoxO pathway. Biogerontology. 2013;14(3):303-23.

[53] Sanders LH, McCoy J, Hu X, Mastroberardino PG, Dickinson BC, Chang CJ, Chu CT, Van Houten B, Greenamyre JT. Mitochondrial DNA damage: Molecular marker of vulnerable nigral neurons in Parkinson's disease. Neurobiol Dis. 2014;70:214-23.

[54] Aleman-Mateo H, Macias L, Esparza-Romero J, Astiazaran-Garcia H, Blancas AL. Physiological effects beyond the significant gain in muscle mass in sarcopenic elderly men: evidence from a randomized clinical trial using a protein-rich food. Clinical interventions in aging. 2012;7:225-34. Epub 2012/08/07.

[55] Milan AM, D’Souza RF, Pundir S, Pileggi CA, Barnett MPG, Markworth JF, Cameron-Smith D, Mitchell C. Older adults have delayed amino acid absorption after a high protein mixed breakfast meal. The Journal of Nutrition, Health \& Aging. 2015;19(8):839-45.

[56] Delimaris I. Adverse Effects Associated with Protein Intake above the Recommended Dietary Allowance for Adults. ISRN Nutrition. 2013;2013:126929.

[57] Gunton JE, Girgis CM, Baldock PA, Lips P. Bone muscle interactions and vitamin D: Bone. 2015 Mar 6. pii: S87563282(15)00077-0. doi: 10.1016/j.bone.2015.02.029

[58] Tanaka K, Kanazawa I, Yamaguchi T, Yano S, Kaji H, Sugimoto T. Active vitamin D possesses beneficial effects on the interaction between muscle and bone. Biochemical and biophysical research communications. 2014;450(1): 482-7.

[59] Boland R, Norman A, Ritz E, Hasselbach W. Presence of a 1,25-dihydroxy-vitamin D3 receptor in chick skeletal muscle myoblasts. Biochemical and biophysical research communications. 1985;128(1):305-11. Epub 1985/04/16.

[60] Choi M, Park H, Cho S, Lee M. Vitamin D3 supplementation modulates inflammatory responses from the muscle damage induced by high-intensity exercise in SD rats. Cytokine. 2013;63(1):27-35.

[61] Mastaglia SR, Seijo M, Muzio D, Somoza J, Nunez M, Oliveri B. Effect of vitamin D nutritional status on muscle function and strength in healthy women aged over sixty-five years. The Journal of Nutrition, Health \& Aging. 2011;15(5):349-54. Epub 2011/04/30.
[62] Tajar A, Lee DM, Pye SR, O'Connell MD, Ravindrarajah R, Gielen E, Boonen S, Vanderschueren D, Pendleton N, Finn JD, Bartfai G, Casanueva FF, Forti G, Giwercman A, Han TS, Huhtaniemi IT, Kula K, Lean ME, Punab M, Wu FC, O'Neill TW. The association of frailty with serum 25hydroxyvitamin D and parathyroid hormone levels in older European men. Age and Ageing. 2013;42(3):352-9. Epub 2012/11/01.

[63] Bischoff-Ferrari HA, Dawson-Hughes B, Staehelin HB, Orav JE, Stuck AE, Theiler R, Wong JB, Egli A, Kiel DP, Henschkowski J. Fall prevention with supplemental and active forms of vitamin D: A meta-analysis of randomised controlled trials. BMJ (Clinical research ed). 2009;339:b3692. Epub 2009/10/03.

[64] Kim MK, Baek KH, Song KH, Il Kang M, Park CY, Lee WY, Oh KW. Vitamin D deficiency is associated with sarcopenia in older Koreans, regardless of obesity: the Fourth Korea National Health and Nutrition Examination Surveys (KNHANES IV) 2009. J Clin Endocrinol Metab. 2011;96(10):3250-6.

[65] Park S, Ham JO, Lee BK. A positive association of vitamin $\mathrm{D}$ deficiency and sarcopenia in 50 year old women, but not men. Clin Nutr. 2013;6(13):00256-2.

[66] Dupuy C, Lauwers-Cances V, van Kan GA, Gillette S, Schott AM, Beauchet O, Annweiler C, Vellas B, Rolland Y. Dietary vitamin D intake and muscle mass in older women. Results from a cross-sectional analysis of the EPIDOS study. The Journal of Nutrition, Health \& Aging. 2013;17(2):119-24.

[67] Seo MH, Kim MK, Park SE, Rhee EJ, Park CY, Lee WY, Baek KH, Song KH, Kang MI, Oh KW. The association between daily calcium intake and sarcopenia in older, nonobese Korean adults: the fourth Korea National Health and Nutrition Examination Survey (KNHANES IV) 2009. Endocr J. 2013;60(5):679-86.

[68] Lips P. Vitamin D deficiency and secondary hyperparathyroidism in the elderly: Consequences for bone loss and fractures and therapeutic implications. Endocr Rev. 2001;22(4):477-501.

[69] Bischoff-Ferrari HA, Willett WC, Wong JB, Stuck AE, Staehelin HB, Orav EJ, Thoma A, Kiel DP, Henschkowski J. Prevention of nonvertebral fractures with oral vitamin $\mathrm{D}$ and dose dependency: A meta-analysis of randomized controlled trials. Arch Intern Med. 2009;169(6):551-61.

[70] Tang BM, Eslick GD, Nowson C, Smith C, Bensoussan A. Use of calcium or calcium in combination with vitamin D supplementation to prevent fractures and bone loss in people aged 50 years and older: A meta-analysis. Lancet. 2007;370(9588):657-66.

[71] Cranney A, Weiler HA, O’Donnell S, Puil L. Summary of evidence-based review on vitamin D efficacy and safety in relation to bone health. Am J Clin Nutr. 2008;88(2):513S$9 \mathrm{~S}$.

[72] Gems D, Doonan R. Antioxidant defense and aging in C. elegans: Is the oxidative damage theory of aging wrong? Cell Cycle. 2009;8(11):1681-7.

[73] Ivanova DG, Yankova TM. The free radical theory of aging in search of a strategy for increasing life span. Folia Med. 2013;55(1):33-41.

[74] Harman D. Aging: A theory based on free radical and radiation chemistry. J Gerontol. 1956;11(3):298-300. 
[75] Finkel T, Holbrook NJ. Oxidants, oxidative stress and the biology of ageing. Nature. 2000;408(6809):239-47.

[76] Joseph AM, Adhihetty PJ, Buford TW, Wohlgemuth SE, Lees HA, Nguyen LM, Aranda JM, Sandesara BD, Pahor M, Manini TM, Marzetti E, Leeuwenburgh C. The impact of aging on mitochondrial function and biogenesis pathways in skeletal muscle of sedentary high- and low-functioning elderly individuals. Aging cell. 2012;11(5):801-9. Epub 2012/06/12.

[77] Wang X, Pickrell AM, Rossi SG, Pinto M, Dillon LM, Hida A, Rotundo RL, Moraes CT. Transient systemic mtDNA damage leads to muscle wasting by reducing the satellite cell pool. Human molecular genetics. 2013;22(19):397686. Epub 2013/06/14.

[78] Derbre F, Gomez-Cabrera MC, Nascimento AL, SanchisGomar F, Martinez-Bello VE, Tresguerres JA, Fuentes T, Gratas-Delamarche A, Monsalve M, Vina J. Age associated low mitochondrial biogenesis may be explained by lack of response of PGC-1alpha to exercise training. Age (Dordrecht, Netherlands). 2012;34(3):669-79. Epub 2011/05/19.

[79] Siu PM, Pistilli EE, Alway SE. Age-dependent increase in oxidative stress in gastrocnemius muscle with unloading. $\mathrm{J}$ Appl Physiol. 2008;105(6):1695-705.

[80] Sullivan-Gunn MJ, Lewandowski PA. Elevated hydrogen peroxide and decreased catalase and glutathione peroxidase protection are associated with aging sarcopenia. BMC geriatrics. 2013;13:104. Epub 2013/10/08.

[81] Chaput JP, Lord C, Cloutier M, Aubertin Leheudre M, Goulet ED, Rousseau S, Khalil A, Dionne IJ. Relationship between antioxidant intakes and class I sarcopenia in elderly men and women. The Journal of Nutrition, Health \& Aging. 2007;11(4):363-9.

[82] Marzani B, Balage M, Venien A, Astruc T, Papet I, Dardevet D, Mosoni L. Antioxidant supplementation restores defective leucine stimulation of protein synthesis in skeletal muscle from old rats. J Nutr. 2008;138(11):2205-11.

[83] Aruoma OI. Nutrition and health aspects of free radicals and antioxidants. Food Chem Toxicol. 1994;32(7): 671-83.

[84] Li Y, Schellhorn HE. New developments and novel therapeutic perspectives for vitamin C. J Nutr. 2007;137(10): 2171-84.

[85] Mustacich DJ, Bruno RS, Traber MG. Vitamin E. Vitam Horm. 2007;76:1-21.

[86] Kaulmann A, Bohn T. Carotenoids, inflammation, and oxidative stress-implications of cellular signaling pathways and relation to chronic disease prevention. Nutrition research (New York, NY). 2014;34(11):907-29.

[87] Rodrigo R, Libuy M, Feliu F, Hasson D. Polyphenols in disease: from diet to supplements. Curr Pharm Biotechnol. 2014;15(4):304-17.

[88] Harasym J, Oledzki R. Effect of fruit and vegetable antioxidants on total antioxidant capacity of blood plasma. Nutrition. 2014;30(5):511-7.

[89] Ashor AW, Siervo M, Lara J, Oggioni C, Afshar S, Mathers JC. Effect of vitamin C and vitamin E supplementation on endothelial function: A systematic review and meta-analysis of randomised controlled trials. Br J Nutr. 2015;113(8):1182-94.

[90] Bouayed J, Bohn T. Exogenous antioxidants-Doubleedged swords in cellular redox state: Health beneficial effects at physiologic doses versus deleterious effects at high doses. Oxid Med Cell Longev. 2010;3(4):228-37.

[91] Bobeuf F, Labonte M, Dionne IJ, Khalil A. Combined effect of antioxidant supplementation and resistance training on oxidative stress markers, muscle and body composition in an elderly population. The Journal of Nutrition, Health \& Aging. 2011;15(10):883-9. Epub 2011/12/14.

[92] Lauretani F, Semba RD, Bandinelli S, Dayhoff-Brannigan M, Giacomini V, Corsi AM, Guralnik JM, Ferrucci L. Low plasma carotenoids and skeletal muscle strength decline over 6 years. J Gerontol A Biol Sci Med Sci. 2008;63(4): 376-83.

[93] Semba RD, Blaum C, Guralnik JM, Moncrief DT, Ricks MO, Fried LP. Carotenoid and vitamin E status are associated with indicators of sarcopenia among older women living in the community. Aging Clin Exp Res. 2003;15(6):482-7.

[94] Dutt V, Gupta S, Dabur R, Injeti E, Mittal A. Skeletal muscle atrophy: Potential therapeutic agents and their mechanisms of action: Pharmacol Res. 2015 Jun 2. pii: S10436618(15)00094-8. doi: 10.1016/j.phrs.2015.05.010.; 2015.

[95] Dolinsky VW, Dyck JR. Experimental studies of the molecular pathways regulated by exercise and resveratrol in heart, skeletal muscle and the vasculature. Molecules. 2014;19(9):14919-47.

[96] Hori YS, Kuno A, Hosoda R, Tanno M, Miura T, Shimamoto K, Horio Y. Resveratrol ameliorates muscular pathology in the dystrophic mdx mouse, a model for Duchenne muscular dystrophy. The Journal of Pharmacology and Experimental Therapeutics. 2011;338(3):784-94.

[97] Wang DT, Yin Y, Yang YJ, Lv PJ, Shi Y, Lu L, Wei LB. Resveratrol prevents TNF-alpha-induced muscle atrophy via regulation of $\mathrm{Akt} / \mathrm{mTOR} / \mathrm{FoxO} 1$ signaling in $\mathrm{C} 2 \mathrm{C} 12$ myotubes. Int Immunopharmacol. 2014;19(2):206-13.

[98] Zheng J, Chen LL, Zhang HH, Hu X, Kong W, Hu D. Resveratrol improves insulin resistance of catch-up growth by increasing mitochondrial complexes and antioxidant function in skeletal muscle. Metabolism. 2012;61(7):95465.

[99] Barger JL, Kayo T, Vann JM, Arias EB, Wang J, Hacker TA, Wang Y, Raederstorff D, Morrow JD, Leeuwenburgh C, Allison DB, Saupe KW, Cartee GD, Weindruch R, Pro1la TA. A low dose of dietary resveratrol partially mimics caloric restriction and retards aging parameters in mice. PLoS One. 2008;3(6):0002264.

[100] Jackson JR, Ryan MJ, Hao Y, Alway SE. Mediation of endogenous antioxidant enzymes and apoptotic signaling by resveratrol following muscle disuse in the gastrocnemius muscles of young and old rats. Am J Physiol Regul Integr Comp Physiol. 2010;299(6):22.

[101] Joseph AM, Malamo AG, Silvestre J, Wawrzyniak N, Carey-Love S, Nguyen LM, Dutta D, Xu J, Leeuwenburgh C, Adhihetty PJ. Short-term caloric restriction, resveratrol, or combined treatment regimens initiated in late-life alter mitochondrial protein expression profiles in a fiber-type specific manner in aged animals. Experimental Gerontology. 2013;48(9):858-68.

[102] Hubbard BP, Sinclair DA. Small molecule SIRT1 activators for the treatment of aging and age-related diseases. Trends Pharmacol Sci. 2014;35(3):146-54.

[103] Wang B, Yang G, Liang X, Zhu M, Du M. Grape seed extract prevents skeletal muscle wasting in interleukin 10 knockout 
mice. BMC Complement Altern Med. 2014;14(162):14726882.

[104] Gordon BS, Delgado Diaz DC, Kostek MC. Resveratrol decreases inflammation and increases utrophin gene expression in the mdx mouse model of Duchenne muscular dystrophy. Clin Nutr. 2013;32(1):104-11.

[105] Gordon BS, Delgado-Diaz DC, Carson J, Fayad R, Wilson LB, Kostek MC. Resveratrol improves muscle function but not oxidative capacity in young $\mathrm{mdx}$ mice. Canadian Journal of Physiology and Pharmacology. 2014;92(3): 243-51.

[106] Bennett BT, Mohamed JS, Alway SE. Effects of resveratrol on the recovery of muscle mass following disuse in the plantaris muscle of aged rats. PLoS One. 2013;8(12):e83518.

[107] Jackson JR, Ryan MJ, Alway SE. Long-term supplementation with resveratrol alleviates oxidative stress but does not attenuate sarcopenia in aged mice. J Gerontol A Biol Sci Med Sci. 2011;66(7):751-64. Epub 2011/04/02.

[108] Carr AC, Bozonet SM, Vissers MC. A randomised crossover pharmacokinetic bioavailability study of synthetic versus kiwifruit-derived vitamin C. Nutrients. 2013;5(11): 4451-61.

[109] Woodside JV, McGrath AJ, Lyner N, McKinley MC. Carotenoids and health in older people. Maturitas. 2015; 80(1):63-8.

[110] Chung HY, Cesari M, Anton S, Marzetti E, Giovannini S, Seo AY, Carter C, Yu BP, Leeuwenburgh C. Molecular inflammation: Underpinnings of aging and age-related diseases. Ageing research reviews. 2009;8(1):18-30. Epub 2008/08/12.

[111] Cornish SM, Chilibeck PD. Alpha-linolenic acid supplementation and resistance training in older adults. Appl Physiol Nutr Metab. 2009;34(1):49-59. Epub 2009/02/24.

[112] Koopman R, van Loon LJ. Aging, exercise, and muscle protein metabolism. Journal of Applied Physiology (Bethesda, Md : 1985). 2009;106(6):2040-8. Epub 2009/01/10.

[113] Balage M, Averous J, Remond D, Bos C, Pujos-Guillot E, Papet I, Mosoni L, Combaret L, Dardevet D. Presence of low-grade inflammation impaired postprandial stimulation of muscle protein synthesis in old rats. J Nutr Biochem. 2010;21(4):325-31. Epub 2009/04/17.

[114] Rieu I, Magne H, Savary-Auzeloux I, Averous J, Bos C, Peyron MA, Combaret L, Dardevet D. Reduction of low grade inflammation restores blunting of postprandial muscle anabolism and limits sarcopenia in old rats. The Journal of Physiology. 2009;587(Pt 22):5483-92. Epub 2009/09/16.

[115] Rousseau JH, Kleppinger A, Kenny AM. Self-reported dietary intake of omega-3 fatty acids and association with bone and lower extremity function. J Am Geriatr Soc. 2009;57(10):1781-8. Epub 2008/09/02.

[116] Siriwardhana N, Kalupahana NS, Moustaid-Moussa N. Health benefits of $n-3$ polyunsaturated fatty acids: Eicosapentaenoic acid and docosahexaenoic acid. Advances in food and nutrition research. 2012;65:211-22. Epub 2012/03/01

[117] Smith GI, Julliand S, Reeds DN, Sinacore DR, Klein S, Mittendorfer B. Fish oil-derived n-3 PUFA therapy increases muscle mass and function in healthy older adults. Am J Clin Nutr. 2015;20.

[118] Robinson SM, Jameson KA, Batelaan SF, Martin HJ, Syddall HE, Dennison EM, Cooper C, Sayer AA. Diet and its relationship with grip strength in community-dwelling older men and women: the Hertfordshire cohort study. J Am Geriatr Soc. 2008;56(1):84-90.

[119] Reinders I, Song X, Visser M, Eiriksdottir G, Gudnason V, Sigurdsson S, Aspelund T, Siggeirsdottir K, Brouwer IA, Harris TB, Murphy RA. Plasma phospholipid PUFAs are associated with greater muscle and knee extension strength but not with changes in muscle parameters in older adults. J Nutr. 2015;145(1):105-12. Epub 2014/10/31.

[120] Abbatecola AM, Cherubini A, Guralnik JM, Andres Lacueva C, Ruggiero C, Maggio M, Bandinelli S, Paolisso G, Ferrucci L. Plasma polyunsaturated fatty acids and age-related physical performance decline. Rejuvenation Research. 2009;12(1):25-32. Epub 2009/02/07.

[121] Russo GL. Dietary n-6 and n-3 polyunsaturated fatty acids: From biochemistry to clinical implications in cardiovascular prevention. Biochemical Pharmacology. 2009;77(6):937-46. Epub 2008/11/22.

[122] Tieland M, Dirks ML, van der Zwaluw N, Verdijk LB, van de Rest O, de Groot LC, van Loon LJ. Protein supplementation increases muscle mass gain during prolonged resistance-type exercise training in frail elderly people: A randomized, double-blind, placebo-controlled trial. Journal of the American Medical Directors Association. 2012;13(8):713-9.

[123] Farnfield MM, Breen L, Carey KA, Garnham A, CameronSmith D. Activation of mTOR signalling in young and old human skeletal muscle in response to combined resistance exercise and whey protein ingestion. Appl Physiol Nutr Metab. 2012;37(1):21-30.

[124] Chale A, Cloutier GJ, Hau C, Phillips EM, Dallal GE, Fielding RA. Efficacy of whey protein supplementation on resistance exercise-induced changes in lean mass, muscle strength, and physical function in mobility-limited older adults. The journals of Gerontology Series A, Biological sciences and Medical Sciences. 2013;68(6):682-90. Epub 2012/11/02.

[125] Wall BT, Hamer HM, de Lange A, Kiskini A, Groen BB, Senden JM, Gijsen AP, Verdijk LB, van Loon LJ. Leucine co-ingestion improves post-prandial muscle protein accretion in elderly men. Clin Nutr. 2013;32(3):412-9.

[126] Dickinson JM, Gundermann DM, Walker DK, Reidy PT, Borack MS, Drummond MJ, Arora M, Volpi E, Rasmussen BB. Leucine-enriched amino acid ingestion after resistance exercise prolongs myofibrillar protein synthesis and amino acid transporter expression in older men. J Nutr. 2014;144(11):1694-702.

[127] Dirks ML, Wall BT, Nilwik R, Weerts DH, Verdijk LB, van Loon LJ. Skeletal muscle disuse atrophy is not attenuated by dietary protein supplementation in healthy older men. $\mathrm{J}$ Nutr. 2014;144(8):1196-203.

[128] Zeanandin G, Balage M, Schneider SM, Dupont J, Hebuterne X, Mothe-Satney I, Dardevet D. Differential effect of long-term leucine supplementation on skeletal muscle and adipose tissue in old rats: an insulin signaling pathway approach. Age. 2012;34(2):371-87.

[129] Vianna D, Resende GF, Torres-Leal FL, Pantaleao LC, Donato J, Jr., Tirapegui J. Long-term leucine supplementation reduces fat mass gain without changing body protein status of aging rats. Nutrition. 2012;28(2):182-9.

[130] Savary-Auzeloux I, Magne H, Migne C, Oberli M, Breuille D, Faure M, Vidal K, Perrot M, Remond D, Combaret L, Dardevet D. A dietary supplementation with leucine and 
antioxidants is capable to accelerate muscle mass recovery after immobilization in adult rats. PloS one. 2013; 8(11):e81495.

[131] Mosoni L, Gatineau E, Gatellier P, Migne C, SavaryAuzeloux I, Remond D, Rocher E, Dardevet D. High whey protein intake delayed the loss of lean body mass in healthy old rats, whereas protein type and polyphenol/antioxidant supplementation had no effects. PLoS One. 2014;9(9):e109098.
[132] de Souza Genaro P, de Medeiros Pinheiro M, Szejnfeld VL, Martini LA. Secondary hyperparathyroidism and its relationship with sarcopenia in elderly women. Arch Gerontol Geriatr. 2015;60(2):349-53.

[133] Pojednic RM, Ceglia L. The emerging biomolecular role of vitamin $d$ in skeletal muscle. Exerc Sport Sci Rev. 2014;42(2):76-81. 